\title{
Dynamic sequential box modelling of inhalation exposure potential in multi-bed patient ward: validation and baseline case studies
}

\author{
Majeed Oladokun, Zhang Lin* \\ Division of Building Science and Technology, City University of Hong Kong, Hong \\ Kong, China; \\ Division of Building Science and Technology, City University of Hong Kong, Hong \\ Kong, China \\ *Correspondence author. Tel: +852 3442 9805; Fax: +852 3442 0443; \\ Email: bsjzl@cityu.edu.hk
}

\begin{abstract}
Macro-models provide a fast simulation tool for exposure assessments and design of control interventions, yet there are concerns about their accuracies. Single-zone based models are known to be inadequate for predicting exposure to near-source emissions, while the complexity of sequential box models (SBM) limits their application to steady-state conditions. However, treating unsteady conditions as steady underestimates peak inhalation exposure potentials, especially near the source. This study employs a sub-configuration validation approach to validate the unsteady SBM, using an R open-source-based numerical solver, for estimating indoor pollutant concentration, exposure and/or infection risks. The validated model is used to assess the performance of ASHRAE S170-2017 baseline specifications for inhalation exposure control in a multi-bed patient ward with air recirculation. In the baseline studies, quanta infective concentration and reference concentration were respectively used as source strength and threshold values for influenza pathogen. Robust design methodology was employed in the experimental design and analysis of the control and noise factors. Results indicate a close relationship between SBM and the sub-configuration validation datasets. Findings also show that concentration gradients exist in SBM with the highest values in the near-field zones. Thus, with SBM, the well-mixed assumption does not necessarily imply equal exposure potentials. Robustness analysis shows that stratum ventilation is three-fold insensitive to the variability in exposure than mixing ventilation. Finally, the results of the case studies revealed that the average
\end{abstract}


inhalation exposure exceeds the influenza reference concentration, thereby suggesting an insufficiency of the baseline conditions to offer protection against inhalation exposure to influenza contagion.

Keywords: Sequential box model; Inhalation exposure; Sub-configuration validation; ASHRAE baseline; multi-bed patient ward; open-source numerical solver

\begin{tabular}{|c|c|c|c|}
\hline \multicolumn{4}{|c|}{ Nomenclature } \\
\hline & Variables & & bscripts/Greek symbols \\
\hline$A_{i}$ & sequential surface area $\left(\mathrm{m}^{2}\right)$ & $a / o a$ & Outdoor \\
\hline$A H U$ & Air Handling Unit & $b$ & Backward \\
\hline$C(t)$ & Temporal pathogen concentration & $f$ & Forward \\
\hline$E(t)$ & $\begin{array}{l}\text { Temporal exposure concentration } \\
\left(\mathrm{pfu} / \mathrm{m}^{3}\right)\end{array}$ & $e$ & Exit \\
\hline$g_{i}(t)$ & $\begin{array}{l}\text { Temporal zone pathogen emission } \\
\text { (pfu/h) }\end{array}$ & $e x$ & Exhaust \\
\hline$H V A C$ & $\begin{array}{l}\text { Heating Ventilation And Air } \\
\text { Conditioning }\end{array}$ & $L$ & Lower \\
\hline$L$ & Contaminant loss rate & $N F$ & Near-Field \\
\hline$m$ & Mixing factor & $r$ & Recirculated \\
\hline$N$ & Air change rate & $s$ & Supply \\
\hline$P_{f}$ & Pathogen penetration factor (-) & $t$ & Total \\
\hline$Q$ & Air flow rates $\left(\mathrm{m}^{3} / \mathrm{h}\right)$ & $U$ & Upper \\
\hline$Q i C$ & Quanta infective Concentration & $i$ & $i$ th locations or Zones \\
\hline$R f C$ & Reference Concentration & $\beta$ & Inter-zonal airflow rates (-) \\
\hline$S_{U V}$ & Pathogen survival (-) & $\eta$ & Filter efficiency (-) \\
\hline$u$ & Air speed & $\mu$ & Variable mean \\
\hline$V$ & Volume $\left(\mathrm{m}^{3}\right)$ & & \\
\hline
\end{tabular}

\section{Introduction}

In the modern society, people spent a large part of their communal life in confined spaces [1], where they are exposed to various environmental agents that may adversely affect their health and wellness [2]. In these environments, only a few of the agents in the voluminous air inhaled hourly, daily, weekly, monthly or yearly, are exhaled while others are trapped in different locations within the human body [3]. The trapped air may contain harmful pathogens to human health. As infectious pathogens may be included in the residue of droplets expelled from human expiratory activities (breathing, coughing, or sneezing, or even in talking) [3], an effective way of reducing indoor related adverse health consequences is to prevent exposures to environmental agents. Data for health risk 
assessments are broadly obtained from numerical simulation and physical experimental methods $[4,5]$. Although physical experiments provide a more reliable estimate, such endeavour is arduous for human exposure risk assessment due to space constraints as well as ethical considerations.

Numerical simulation methods are excellent tools for scenarios that are either difficult or too expensive to carry-out under physical conditions [6]. The numerical simulation approach can be broadly divided into micro (computational fluid dynamics) and macro (single-zone or multi-zone) modelling [7]. Although experiments with computational fluid dynamics (CFD) methods are more accurate than those from the single-zone or multi-zone models, CFD methods are computationally expensive [8] and time-inefficient [9]. Macromodels as tools for exposure assessments have been used for decades. They provide a simplified and time-efficient approach for exposure and/or risk quantifications. At the basic level of macro-model is the one-box (single-zone) model (Equation 1), which treat an entire space as a single volume and assume spatial uniformity of pollutant concentration [6].

$$
V \frac{d C(t)}{d t}=g(t)+P Q C_{S}(t)-Q C(t)-L(t)
$$

Where $V$ is the zone volume $\left(\mathrm{m}^{3}\right), C(t)$ is the temporal variation of room concentration $\left(\mathrm{mg} / \mathrm{m}^{3}, \mu \mathrm{g} / \mathrm{m}^{3}, \mathrm{cfu} / \mathrm{m}^{3}\right.$, or $\left.\mathrm{pfu} / \mathrm{m}^{3}\right) ; C_{S}(t)$ is the inlet contaminant concentration, which may be directly outdoor concentration or a mixture of outdoor and recirculated concentration; $g(t)$ is the emission rate of contaminant in the zone at time $t(\mathrm{mg} / \mathrm{h}, \mu \mathrm{g} / \mathrm{h}, \mathrm{cfu} / \mathrm{h}, \mathrm{pfu} / \mathrm{h}$, etc. $)$; $Q$ is the airflow rates into the zone $\left(\mathrm{m}^{3} / \mathrm{h}\right) ; P$ is a coefficient (dimensionless) that account for the loss of contaminant on entering the zone due to the joint effects of air cleaning, air disinfection, and loss other than the zonal loss due to plate-out and/or decay (chemical, biological, or others). Accordingly, $P$ equals unity when there are no losses and nullity in the absence of the outdoor contaminants entry and/or room air recirculation; $L(t)$ is the rate of contaminant removal within the zone by plate-out, in-room filtration (such as portable filtration devices), in-room disinfection (such as upper room ultraviolet germicidal irradiation devices), biological decay, and chemical reaction; and $t$ is the time (h). 
Although the one-box approach affords mathematical simplicity, treating a whole space as a single volume masks the spatial variability in exposure [7] and underestimates source proximate exposure intensity [6, 9-13]. Regardless of these limitations, several indoor exposure studies, including the Wells-Riley infection risk model [14-17], are based on the one-box model. Sequential box models (SBM) provide useful alternatives that account for the limitations in one-box models $[6,10,18]$. Results of SBM for pollutant dispersals compare well with full-scale experiments [10] and CFD [19]. Fig. 1 shows the schematic of an SBM.

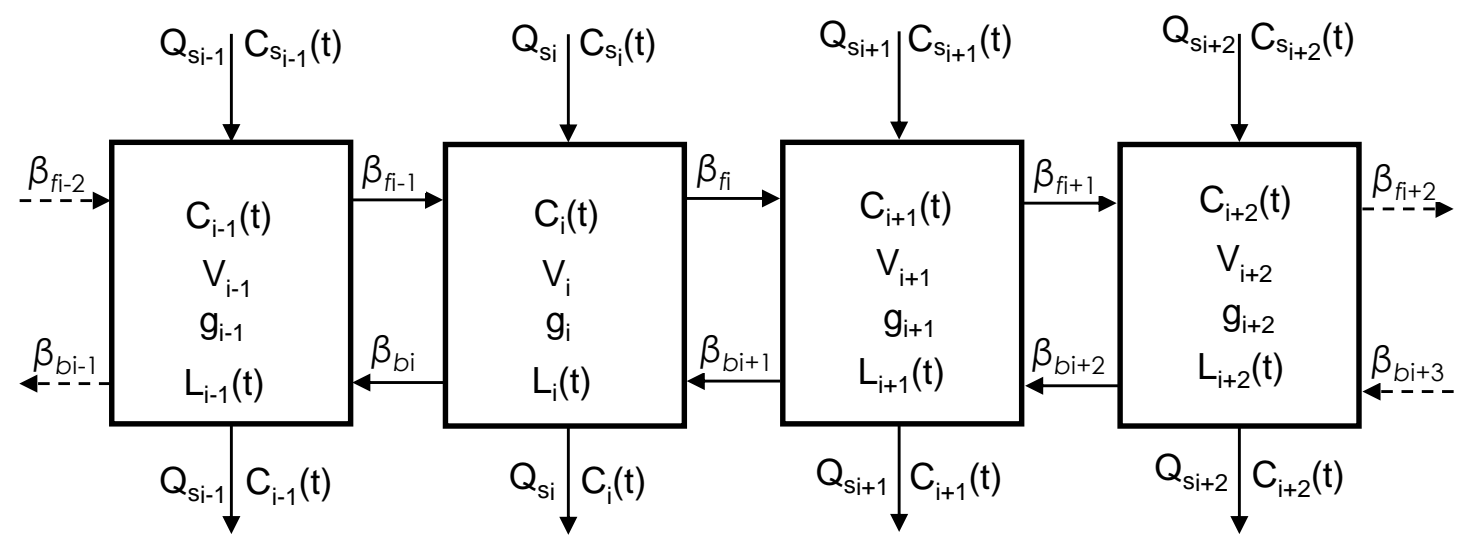

Fig.1. Schematic of general sequential box model for temporal and spatial evolution of contaminant in an enclosure.

It consists of multiple (sequential) boxes that contain the features of a one-box model; hence, the contaminant in each box is assumed to be well-mixed. Also, each adjacent boxes communicate via the inter-zonal air flow rates $\beta_{f}$ and $\beta_{b}$; where the subscripts $f$ and $b$, respectively indicate the forward and backward inter-zonal air flow. However, there is no zonal airflow to and from the foremost and rearmost zones. As SBM is flexible, the parameters in each of the zones can be similar or vary to suit specific applications. For instance, SBM can be formulated for multi-zones with a horizontal arrangement such as exposure assessment in aircraft $[18,20]$ or patient ward [13] environments; and/or vertical arrangements, such as in upper air disinfection with ultraviolet germicidal irradiation systems [21]. Equation (2) shows the general form of coupled ordinary differential equations (ODEs) for the SBM. 


$$
\begin{aligned}
V_{i} \frac{d C_{i}(t)}{d t} & =g_{i}+Q s_{i} C s_{i}(t)+\beta_{f i-1} C_{i-1}(t)+\beta_{b i+1} C_{i+1}(t) \\
& -\left(\beta_{b i}+\beta_{f i}+Q s_{i}\right) C_{i}(t)-L_{i}(t)
\end{aligned}
$$

The parameters in Equation (2) are similar to that of the one-box model, i.e., Equation (1). However, as the number of ODEs increases with zones, the complexity of obtaining their close-forms increases. Thus, due to complexity, the closed-form of SBM are somewhat unavailable, thereby limiting the use of SBM to the assumption of steady-state conditions $[13,21]$, which may underestimate the peak exposure thresholds from highly variable emission over a period below the time to attain the steady-state. Although there are unsteady-state close-form of mass balance model for exposure assessments [15, 22], they are limited to one-box models. Thus, these formulations suffer from the limitations mentioned above of one-box modelling, i.e., underestimation of source-proximate exposure. As the closed form of Equation (2) may be unavailable, the non-closed form is numerically solved, using, for example, fourth-order Runge-Kutta method [6, 7].

The reliability of SBM outputs largely depends on the accuracy of the input variables, which include the emission source strength, the well-mixed assumption in the model formulation, and the accuracy of the numerical solution scheme. To improve reliability, it is essential to minimise these error sources as much as possible. For the source strength, the conventional approach uses quanta generation rate proposed by Riley et al. [14]. Although this approach had been widely employed, it has a lot of limitations, which include lack of consideration for the coupled effects of host susceptibility and pathogen infectivity factors, deviation from the Wells [3] quantum of infection postulates [23], in terms of droplet nuclei source strength as that which infect 63.2 per cent of the susceptible population; and the measurement unit as being similar to that of bioassay responsive dose (colony forming unit per cubic meter or plague forming unit per cubic meter). Further, the conventional approach lacks information on threshold limit, which in addition to emission source strength are essential for human exposure risk assessments [6, 24]. These limitations prompted a recently proposed WellsBenchmark-Dose method [23] (WBMD) that couples Wells' quantum of infection theory [3] with benchmark-dose modelling [25-27], to retrospectively quantify pathogen source strength and threshold limit, from epidemiological outbreak datasets. The source strength and threshold limits are termed quanta infective concentration (QiC) and reference 
concentration (RfC) respectively. Using WBMD method the QiC and RfC for influenza is reported [23] as $68.6 \mathrm{pfu} / \mathrm{m}^{3}$ and $0.0796 \mathrm{pfu} / \mathrm{m}^{3}$.

On the reliability of the well-mixed assumption, the use of effectiveness coefficient is recommended [7], with values above and below unity representing well-mixed and shortcircuit or non-uniform mixed conditions respectively. SBM and other mass-balanced based macro modelling techniques are inappropriate for enclosed spaces with short-circuit or nonuniform mixed conditions. Estimating effectiveness coefficient involves the determination of mean air age distribution in a mock-up similar to the space of interest [7]. However, ascertaining the suitability of SBM (or other mass balance models) for indoor exposure assessments is scarce in the body of existing literature. Majeed et al. [28] reported, for a patient ward mockup, the effectiveness coefficients under mixing and stratum air distribution as nearly or above unity, suggesting a well-mixed environment and suitability of SBM for the ward the air distribution systems.

In addition to the inherent errors and uncertainties in the model formulation, there is a growing concern about the users' induced variations in numerical simulation outcomes. It has been observed [29] that, the accuracy of a numerical simulation depends largely not only on the theoretical fundamentals but also on the users' experience. Ferziger et al. [30] remarked that the differences between numerical solutions from different authors using similar models exceed that of the same author using different models. Recent studies [31, 32] about the user-dependency effects on the accuracy of building performance diagnosis outcomes reported varying results among different teams of simulators.

As "the judicial presumption of innocence does not hold in numerical simulations, their results are wrong, until proven otherwise." [33]. Therefore, validation studies are imperative to ensure the accuracy, reliability, and trustworthiness of numerical simulation for indoor environment studies [31]. It is sufficient, for validating purposes, to employ data from existing studies that are similar to the problem under study. Nonetheless, in the absence of complete data for the exact problem at hand, sub-configuration validation becomes a good alternative as demonstrated in earlier numerical simulation studies [34-36]. Despite the applications in indoor exposure and/or infection risk assessments [18, 20, 21], limited studies exist on validation of SBM to ascertain the accuracy of not only the numerical 
simulation tools but also reduce the users' induced variations. In the past decades, the use of open-source tools is becoming typical for science, engineering, and other applications. These open-source tools are robust in that various users globally contribute freely to their development thereby making the extension of their capabilities continuous. As numerical modelling and simulation involve a series of uncertainties that may impact the accuracy of their results, their validation becomes essential [31].

The international healthcare standards, such as ASHRAE S170 [37], CDC [38], and HTM 03-01 [39] allow air recirculation in some healthcare spaces. Regardless, room air recirculation is seldom considered [40, 41]. For instance, in its provision for patient wards, ASHRAE S170-2017 [37] specifies (Tables 7.1, 8.1, and 9.1) the recirculation as "NR" (no requirements) and "No" (not permitted); with further notes that recirculation is permitted in spaces other than where "No" is specified for recirculation. Further, Sections 7.1, 8.1 and 9.1 (subparagraph [a][5]) recommend that, for spaces with recirculation by room units, “...the portion of the minimum total air changes per hour required for a space that is greater than the minimum outdoor air changes per hour required component may be provided by recirculating room HVAC units". Further, for spaces where recirculation is permitted (i.e., where "No" is not given), ASHRAE S170-2017 [37] specifies the use of a filter with minimal efficiency reporting value (MERV) of 6.0 (i.e., MERV 6 filter). Regardless of these provisions, air recirculation in the patient ward is seldom considered in exposure assessments and the air hygiene systems' performance for exposure control under ASHRAE S170-2013 specification is unclear.

The objectives of this study include validating SBMs, using $\mathrm{R}$ open-source numerical solver, for simulating temporal and spatial distribution of indoor pollutant concentration (and associated exposure and/or infection risks), under a varying combination of air distribution, dilution ventilation flow rates, air cleaning, and air disinfection. It also demonstrates the use of QiC (as emission source) and RfC (as threshold limits) in designing air hygiene system for inhalation exposure control. Lastly, the study evaluates the performance of air hygiene system design parameters, under ASHRAE S170-2017 [37] specifications, for inhalation exposure control. The article is structured as follows. Section 2 describes the methodology by first introducing the study framework. It further describes the sub-configuration validation dataset employed in the study. Also, Section 2 discusses 
the details of the patient ward for the case study under ASHRAE S170-2017 [37] baseline specifications. Further, Section 2 briefly introduces the open-source numerical tools for simulating the SBMs. Section 3 presents the findings as well as detailed discussions with implications on designing air hygiene systems in respect of ASHRAE S170-2017 [37] specifications for patient ward applications. Lastly, Section 4 concludes the study and provides some recommendations for further studies.

\section{Methodology}

\subsection{Study framework}

The methodology of this study involves the sequential box model (SBM), based on the mass balance equation, which incorporates the effects of non-uniformity in indoor pollutant dispersal and exposure assessments. This study is divided into two main parts. Firstly, the study validates SBM using deSolve (solver) package [42] in R 3.4.2 [43] environment. Although the deSolve package is reported as suitable for solving systems of ordinary and partial differential equations [42, 44], limited validation studies exist on its application, especially for building performance diagnosis in general and indoor exposure risk assessment in particular. As a result, the present study carried out sub-configuration validation with data from existing studies $[13,19,21,45]$. The aim of the validation is in twofold: the suitability of the solver to reproduce the evolution of pollutant concentration with minimal deviations and capability of the experimenters in solving exposure assessment related problems, thereby reducing possible user-related errors. Secondly, with the validated SBM, the study carries out case studies of effective air hygiene system design performance for controlling inhalation exposure to influenza contagion under ASHRAE S170-2017 [37] specifications for a patient ward. For these case studies, the experimental design and analysis involve a Taguchi robust design method. Robust design methods aim at system designs that are insensitive to sources of variability, which are often beyond the control of system designers [46]. Details of the procedures are presented in subsequent sections.

\subsection{Sub-configuration validation of Sequential Box Model}

Sub-configuration validation is required where complete data to simulate every aspect of a problem is unavailable [36]. As full data combining every aspect of air hygiene systems for the control of inhalation exposure is scarce in the existing literature, this study employs sub- 
configuration validation methods with data from existing studies [13, 19, 21, 45]. The datasets consist of the performance of dilution ventilation and filtration [45], hospital wards airborne infection risk [13], the performance of upper-air UVGI in ventilated rooms [19], and transient pathogen concentration decay with air disinfection [21]. The followings are the details of the datasets employed for the sub-configuration validation studies.

\subsubsection{Dilution ventilation and air filtration performance, Mumma [45]}

Mumma [45] compared contaminant transport and filtration issues under variable air volume (VAV) system (Fig. 2a) and dedicated outdoor air system (DOAS) (Fig. 2b). In its approach, the study developed a mass balance model for a three-zone office. Although the three zones are assumed to be physically separated, they are served by a typical air handling unit, which makes the model building appear as SBM without inter-zonal air exchange. 


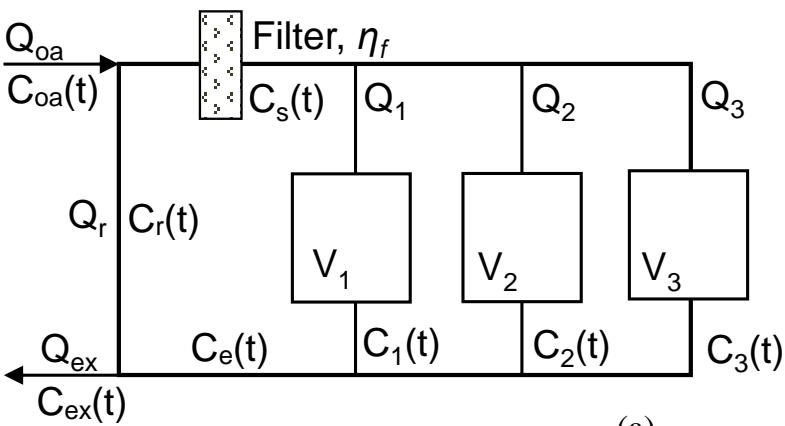

(a)

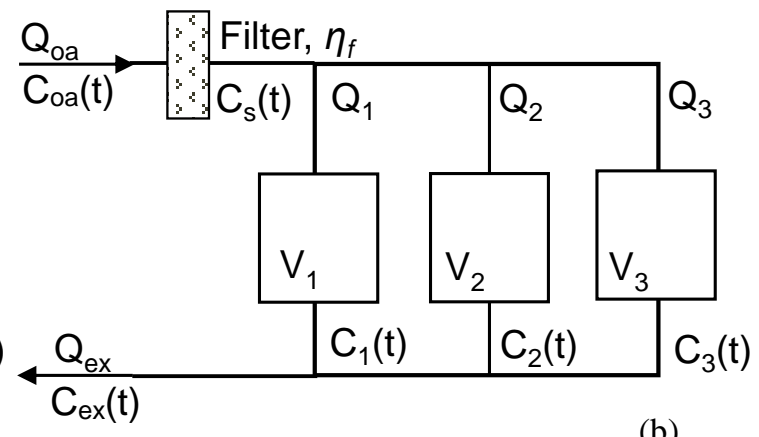

(b)

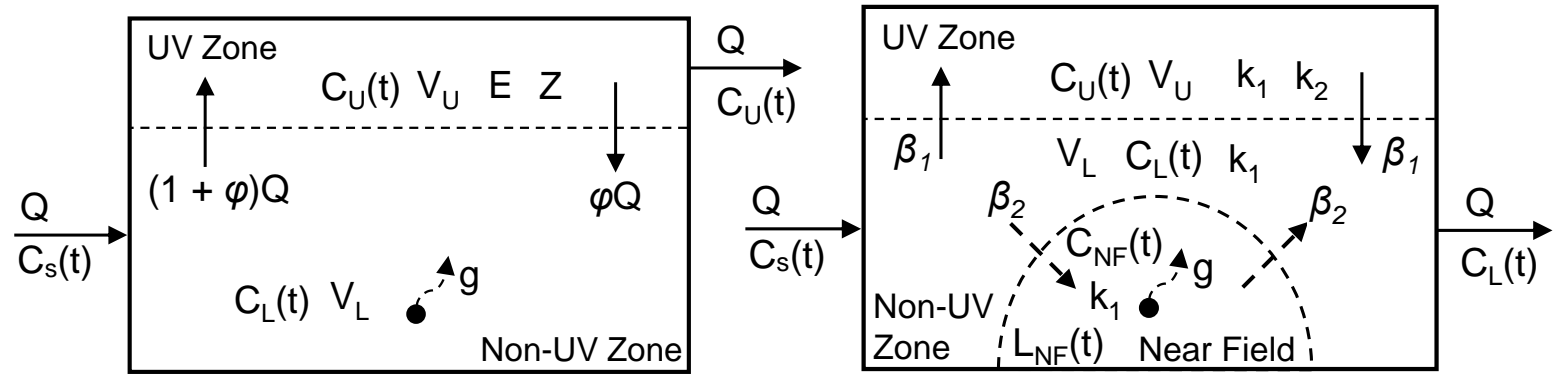

(c)

(d)

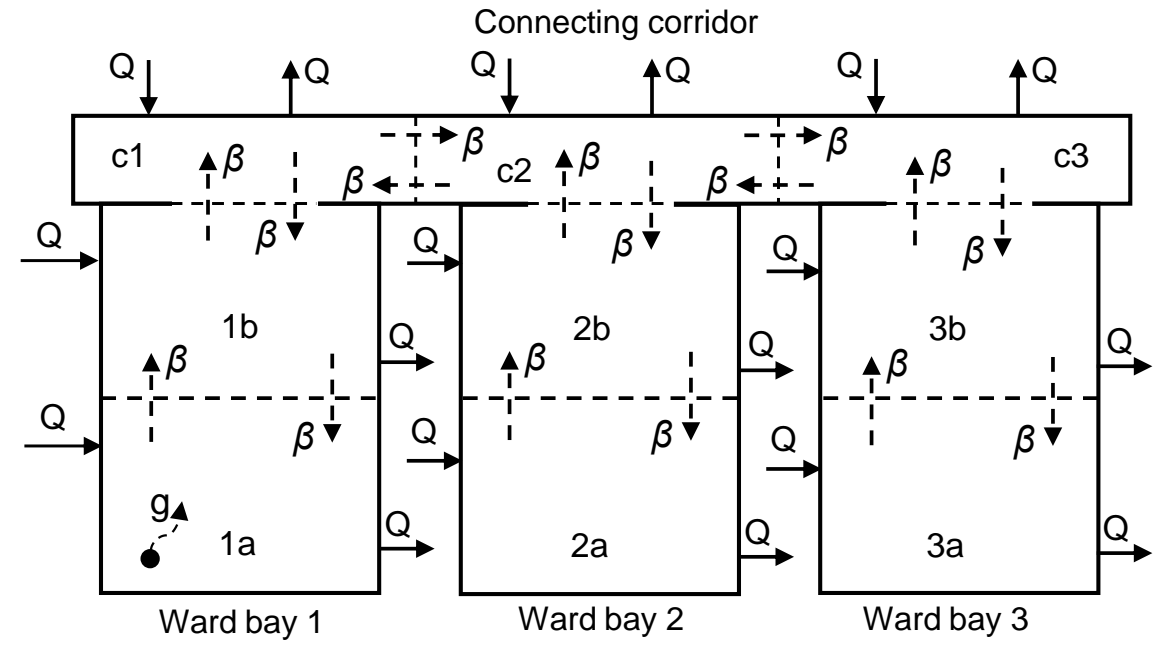

(e)

Fig. 2. Setup of sub-configuration validation cases from earlier studies of: (a) Mumma [45] VAV, (b) Mumma [45] DOAS, (c) Noakes et al. [19] upper-air UVGI performance, (d) Nicas et al. [21] pathogen transient concentration decay, and (e) Noakes et al. [13] hospital wards airborne infection risk.

The general SBM reduces to the standard one-box model if the inter-zonal airflow rates are zero [18], i.e., when there is no air exchange between zones. Hence, the SBM earlier described is applicable, except that the inter-zonal flow rates are zero. Other differences between the reference case and air hygiene SBM are the absence of air disinfection, personal protection, and internal source emission rates. However, the contaminant source is an outdoor pulse emission over a short period. The original study consists of two cases of VAV 
and DOAS dilution ventilation with and without filtration. The case with filtration has respective filter efficiencies of $98 \%$ and $80 \%$ for DOAS and VAV systems.

Table 1 Simulation parameters for Mumma [45] sub-configuration validation case

\begin{tabular}{lll}
\hline \multirow{2}{*}{ Items } & Details & DOAS \\
\cline { 2 - 3 } & VAV & \\
\hline Space volumes $\left(\mathrm{m}^{3}\right)$ & & 279.0 \\
$\quad$ Zone 1 & 279.0 & 2508.0 \\
$\quad$ Zone 2 & 2508.0 & 2787.0 \\
$\quad$ Zone 3 & 2787.0 & 113.26 \\
Total airflow $\left(\mathrm{m}^{3} / \mathrm{min}\right)$ & 453.05 & 113.26 \\
Outdoor airflow $\left(\mathrm{m}^{3} / \mathrm{min}\right)$ & 113.26 & \\
Zone airflow $\left(\mathrm{m}^{3} / \mathrm{min}\right)$ & & 5.67 \\
$\quad$ Zone 1 & 28.35 & 50.96 \\
$\quad$ Zone 2 & 254.81 & 56.63 \\
$\quad$ Zone 3 & 169.90 & \\
Filter efficiency $(\%)$ & & 0.0 \\
$\quad$ Case 1 & 0.0 & 98.0 \\
$\quad$ Case 2 & 80.0 & \\
Source & & Near outdoor air inlet \\
$\quad$ Location & Near outdoor air inlet & 5.0 \\
Pulse duration (min) & 5.0 & 10.0 \\
$\quad$ Generation $\dagger\left(\mu \mathrm{g} / \mathrm{m}^{3}\right)$ & 10.0 & 60.0 \\
\hline Simulation periods (min) & 60.0 & \\
\hline$\dagger$ Temporal evolution of contaminant is normalised by the peak \\
concentration of DOAS under Case 1 (i.e. filtration efficiency equals \\
zero). Hence, emission rates can be assumed as any number
\end{tabular}

Table 1 presents the necessary input parameters for the model validation cases. As the contaminant source is a pulse as a function of time, it may be difficult to have a closed form of the differential equations. A system of ODEs was developed for each of the cases. The SBM of these setups is numerically solved for the two cases. The procedure of solving the SBM follows the method described in Appendix A. Results are presented as dimensionless quantity normalised by the peak concentration of DOAS at zero filtration efficiency. The SBM simulation results and findings from Mumma [45] study are compared for subconfiguration validation of dilution ventilation and air filtration performance.

\subsubsection{Performance of upper-air UVGI in ventilated rooms, Noakes et al. [19]}

Noakes et al. [19] compared the performance of upper air ultraviolet germicidal irradiation (UVGI) devices with analytical and CFD methods. An enclosed environment (Fig. 2c) with 
upper air UVGI devices is divided into two zones, a lower zone that include pollutant source and an upper zone with UVGI device. Mass balance based one-box model is applied to each of the zones with uniform mixing assumptions in them. It is also assumed that there is an inter-zonal exchange between the upper and lower zones. Dilution ventilation is supply and extracted from the lower and upper zones respectively.

Table 2 Simulation parameters for Noakes et al. [19] sub-configuration validation case

\begin{tabular}{|c|c|}
\hline Items & Details \\
\hline \multicolumn{2}{|l|}{ Zone volumes $\dagger\left(\mathrm{m}^{3}\right)$} \\
\hline Zone 1 (Upper) & 7.08 \\
\hline Zone 2 (Lower) & 24.92 \\
\hline \multicolumn{2}{|l|}{ Total outdoor airflow (/h) } \\
\hline Case 1 & 3.0 \\
\hline Case 2 & 6.0 \\
\hline Case 3 & 9.0 \\
\hline Inter-zonal outdoor airflow ( $\left.\mathrm{m}^{3} / \mathrm{min}\right)$ & $3.6 \times$ outdoor airflow \\
\hline \multicolumn{2}{|l|}{ Average upper zone irradiance, Ep $\left(\mathrm{J} / \mathrm{m}^{2} \cdot \mathrm{s}\right)$} \\
\hline No UV & 0.0000 \\
\hline Type 1 & 0.0494 \\
\hline Type 2 & 0.0706 \\
\hline Type 3 & 0.1200 \\
\hline Pathogen & Serratia marcescens \\
\hline Pathogen susceptibility constant, Z (m²/J) & 0.10 \\
\hline \multicolumn{2}{|l|}{ Source } \\
\hline Location & Zone 2 \\
\hline Generation (cfu/s) & 1.2 \\
\hline Simulation periods (min) & 90 \\
\hline
\end{tabular}

With these assumptions, a system of coupled ODEs, similar to the SBM, was developed for the zones. However, to simplify the solution, the study assumed a steady state condition in the zones. On the contrary, in the SBM model presented in the current study, no steady state assumptions were made. This is useful to estimate transient concentration build-up rather than a steady state in a zone. Noakes et al. [19] employed this model to assess the concentration decay of Serratia marcescens pathogen in a room with upper air UVGI. Table 2 presents the details of the input parameters for the simulation. The procedure of solving the SBM follows the method described in Appendix A. The SBM simulation results and 
findings from Noakes et al. [19] study are compared for sub-configuration validation of biological inactivation of the airborne pathogen under UVGI devices.

\subsubsection{Transient pathogen concentration decay with air disinfection, Nicas et al. [21]}

The study of Nicas et al. [21] developed a three-zone model (Fig. 2d) to assess the transient accumulation and/or decay of airborne pathogen concentration in a patient room with upper air UVGI systems. It divided the patient room into the upper irradiated zone and lower nonirradiated zone. Additionally, the non-irradiated zone is further divided into near-field and far-field zones, respectively representing the near emission source and the rest of the nonirradiated zones. Dilution ventilation is supplied and removed from the non-irradiated lower zone. The well-mixed condition was assumed in each of the zones with inter-zonal exchanges between them. Mass balance-based models were developed for the irradiated zone, non-irradiated zone, and the near-field zone. Thus, a system of coupled ODEs, similar to the SBM, were developed.

Table 3 Simulation parameters for Nicas et al. [21] sub-configuration validation case

\begin{tabular}{lc}
\hline Items & Details \\
\hline Zone volumes $\left(\mathrm{m}^{3}\right)$ & \\
Zone 1 (Upper) & 11.2 \\
Zone 2 (Lower) & 50.7 \\
Zone 3 (Near Field) & 2.1 \\
Total outdoor airflow $\left(\mathrm{m}^{3} / \mathrm{min}\right)$ & 2.0 \\
Inter-zonal outdoor airflow $\left(\mathrm{m}^{3} / \mathrm{min}\right)$ & \\
Upper/Lower Zones & 28.0 \\
Near/Far Field Zones & 9.6 \\
Rate constant $(/ \mathrm{min})$ & \\
Biological decay $\left(\mathrm{k}_{1}\right)$ & 0.00235 \\
UV inactivation $\left(\mathrm{k}_{2}\right)$ & 1.28 \\
Pathogen & Mycobacterium. bovis \\
Contaminant & \\
Location & All \\
Initial concentration $\left(\# / \mathrm{m}^{3}\right)$ & 100 \\
Simulation periods (min) & 20 \\
\hline
\end{tabular}

This model is suitable for assessing the transient accumulation of pollutant at the proximate of an infectious patient as well as spaces away from it. The model is also suitable for assessing transient concentration decay such as when an infected person leaves a room, e.g., 
hospital waiting and examination/consulting rooms. Nicas et al. [21] employed the model to assess the concentration decay of $M$. bovis pathogen in a room with upper air UVGI. Table 3 presents the details of the input parameters for the simulation. The procedure of solving the SBM follows the method described in Appendix A.

\subsubsection{Hospital wards airborne infection risk assessments Noakes et al. [13]}

The study of Noakes et al. [13] assessed the role of airflow parameters on the risk of airborne disease transmission in hospital wards. The study considered a hypothetical hospital ward layout (Fig. 2e) with three identical six-bedded bays, which open to a common corridor. Each bay was divided into two identical zones with three occupants each, thereby given a total ward occupancy of 18 patients. Also, the common corridor was divided into three zones to match each of the adjacent wards. It is assumed that the wards operate with only dilution ventilation, under the well-mixed condition with inter-zonal exchanges between the zones.

Table 4 Simulation parameters for Noakes et al. [13] sub-configuration validation case

\begin{tabular}{lc}
\hline Items & Details \\
\hline Zone volumes $\uparrow\left(\mathrm{m}^{3}\right)$ & 78.0 \\
$\quad$ Zone $1 \mathrm{a}, 2 \mathrm{a}, 3 \mathrm{a}$ & 78.0 \\
Zone $1 \mathrm{~b}, 2 \mathrm{~b}, 3 \mathrm{~b}$ & 24.0 \\
Zone $\mathrm{C} 1, \mathrm{C} 2, \mathrm{C} 3$ & 27.0 \\
Total airflow $\left(\mathrm{m}^{3} / \mathrm{min}\right)$ & 3.0 \\
Zonal outdoor airflow $\left(\mathrm{m}^{3} / \mathrm{min}\right)$ & \\
Inter-zonal outdoor airflow $\left(\mathrm{m}^{3} / \mathrm{min}\right)$ & 9.0 \\
$\quad$ Case 1 & 27.0 \\
$\quad$ Case 2 & Mycobacterium tuberculosis \\
Pathogen & \\
Source & Zone $1 \mathrm{a}$ \\
$\quad$ Location & 30.0 \\
$\quad$ Generation (quanta/h) & 170 \\
\hline Simulation periods $(\mathrm{h})$ & \\
\hline The specified total ward ventilation of $27.0 \mathrm{~m}^{3} / \mathrm{min}$ and total $\mathrm{ward}^{3}$ \\
air change rate of 3.0 per hour, give a total ward volume of $540 \mathrm{~m}^{3}$. \\
The total volume is prorated between the ward and corridors
\end{tabular}

Based on mass balance formulation, the study developed coupled ODEs for the zones to estimate the spatial distribution of infection cases under varying ventilation flow and interzonal air exchange. Further details of the problem setup are given in Table 4. Thus, with multi-bed ward zones connected by inter-zonal exchange, the case scenarios in this study fit 
into the SBM construct, thereby useful for the sub-configuration validation. However, unlike the method presented in this study, Noakes et al. [13] assumed steady-state conditions for mathematical simplicity. As pollutant dispersal, especially near the source, may be unsteady, the approach presented in Noakes et al. [13] may suffer (similar to uniform mixing assumption in the one-box model) from the problem of underestimating exposure intensity near the source. The procedure of solving the SBM follows the method described in Appendix A.

\subsection{Case study of air hygiene system performance in multi-bed patient ward under ASHRAE specifications}

\subsubsection{Physical model}

The SBM is suitable for assessing human exposure in enclosed environment $[10,19,47$, 48]. However, as space layouts influence air hygiene system performance as well as pollutant dispersal, it is essential to select ward layout for effective air hygiene system design properly. Also, SBM is valid for analysing enclosed spaces under uniform mixing conditions, which can be determined with experiments in a mock-up similar to the space of interest [7]. Further, the SBM requires the inter-zonal airflow rates, that are either estimated from mean air speed (obtain from intermediate experiments or historical records) and the free surface area between the sequential zones $[6,18]$ or through iterative procedures $[10$, $47,48]$.

For the ASHRAE baseline cases, this study selects a three-bed patient ward mock-up (Fig. 3a) measuring $8.8 \mathrm{~m} \times 6.1 \mathrm{~m} \times 2.4 \mathrm{~m}$ high. Following the Department of Health [49] specification of mean occupancy density in a patient ward $\left(16 \mathrm{~m}^{2}\right.$ per bed space), the mockup ward (total floor area $\approx 54 \mathrm{~m} 2$ ) is suitable as a 3-bed patient room (required $16 \times 3=48$ $\mathrm{m}^{2}$ ). The mock-up ward provides an experimental test bed to the effectiveness coefficient (uniform mixing conditions), average air speed (air distribution) for estimating the interzonal airflow rates, and air change effectiveness. Our earlier study [28] in the patient ward mock-up considered mixing ventilation (MV) [50] and stratum ventilation (SV) $[35,51]$. The study reported the mean air speed as 0.057 and $0.170 \mathrm{~m} / \mathrm{s}$ for MV and SV respectively and found (for both MV and SV) the effectiveness coefficient and air change effectiveness as greater than or equal to unity; thereby suggesting that the room air is uniformly mixed, 
as well as effectively utilising the supply air under both MV and SV systems. Hence, SBM is suitable to model the patient ward. Consequently, the current study considered the same mock-up ward under the two air distribution systems (i.e., MV and SV). While the MV configuration (Fig. 3b) consists of ceiling mounted supply and return outlets, the SV setup (Fig. 3c) comprises supply and return outlets located at $1.3 \mathrm{~m}$ height from the floor level on each longer sides of the ward mock-up.

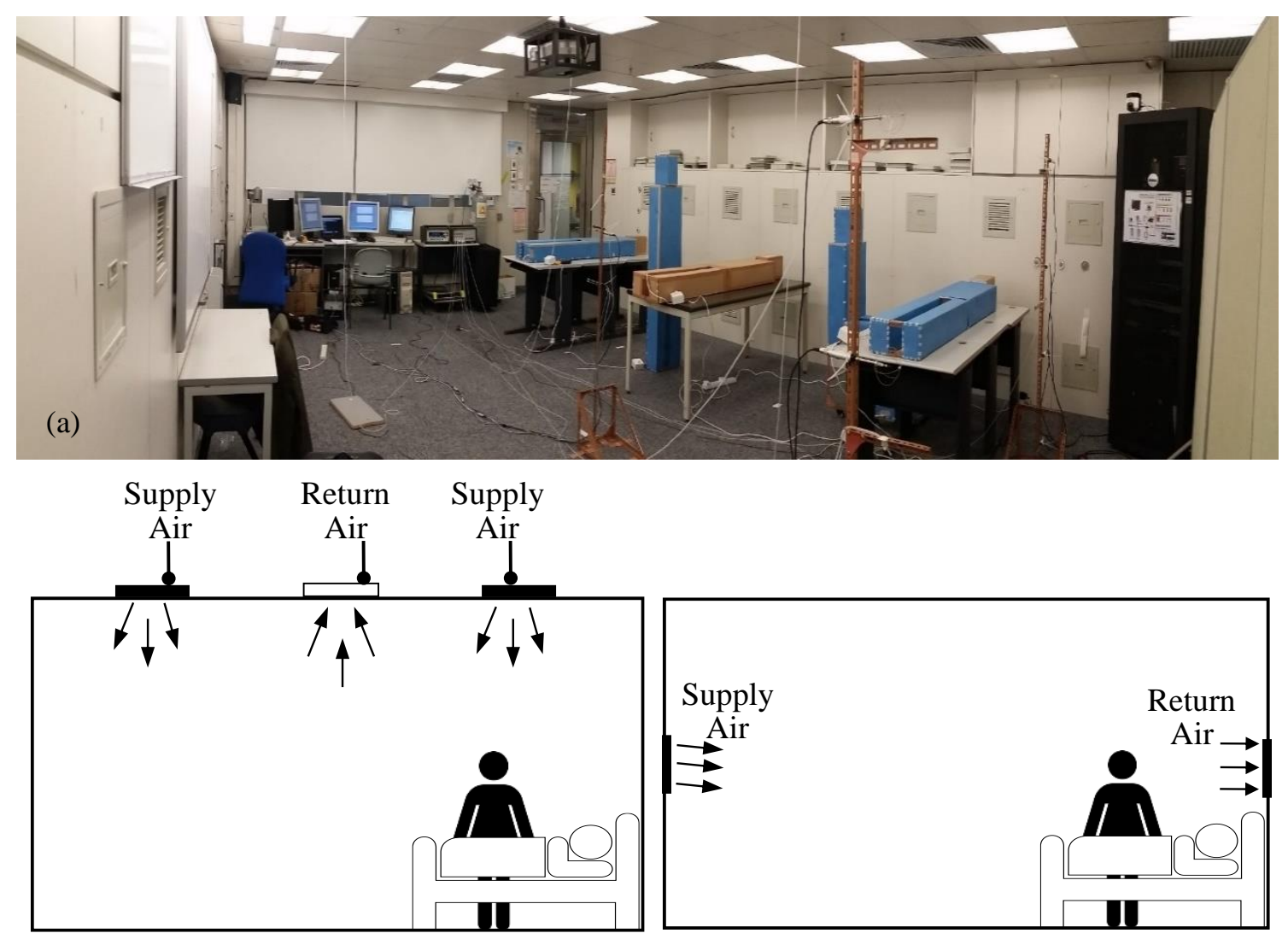

(b)

(c)

Fig. 3. Physical model showing (a) The three-bed patient ward mock-up with schematic of air distribution systems under (b) Mixing ventilation and (c) Stratum ventilation.

\subsubsection{Sequential box model of patient ward air hygiene system with recirculation}

Fig. 4 presents the schematic of the SBM for the three-bed patient ward. A single patient ward is partitioned with virtual walls into multiple zones with volume, $V_{i}\left(\mathrm{~m}^{3}\right)$, which share airflow across the boundaries but prevent inter-zonal air exchange between non-adjacent zones. An index source disseminates infectious agents into the air at a rate of $g_{i}(\mathrm{pfu} / \mathrm{h})$. Upon leaving the source, the exhaled pathogens become droplet nuclei that remain 
suspended in the air for a long time unless they naturally die off, inhale by exposed susceptibles, removed by ventilation, cleaned by filtration or killed by disinfection.

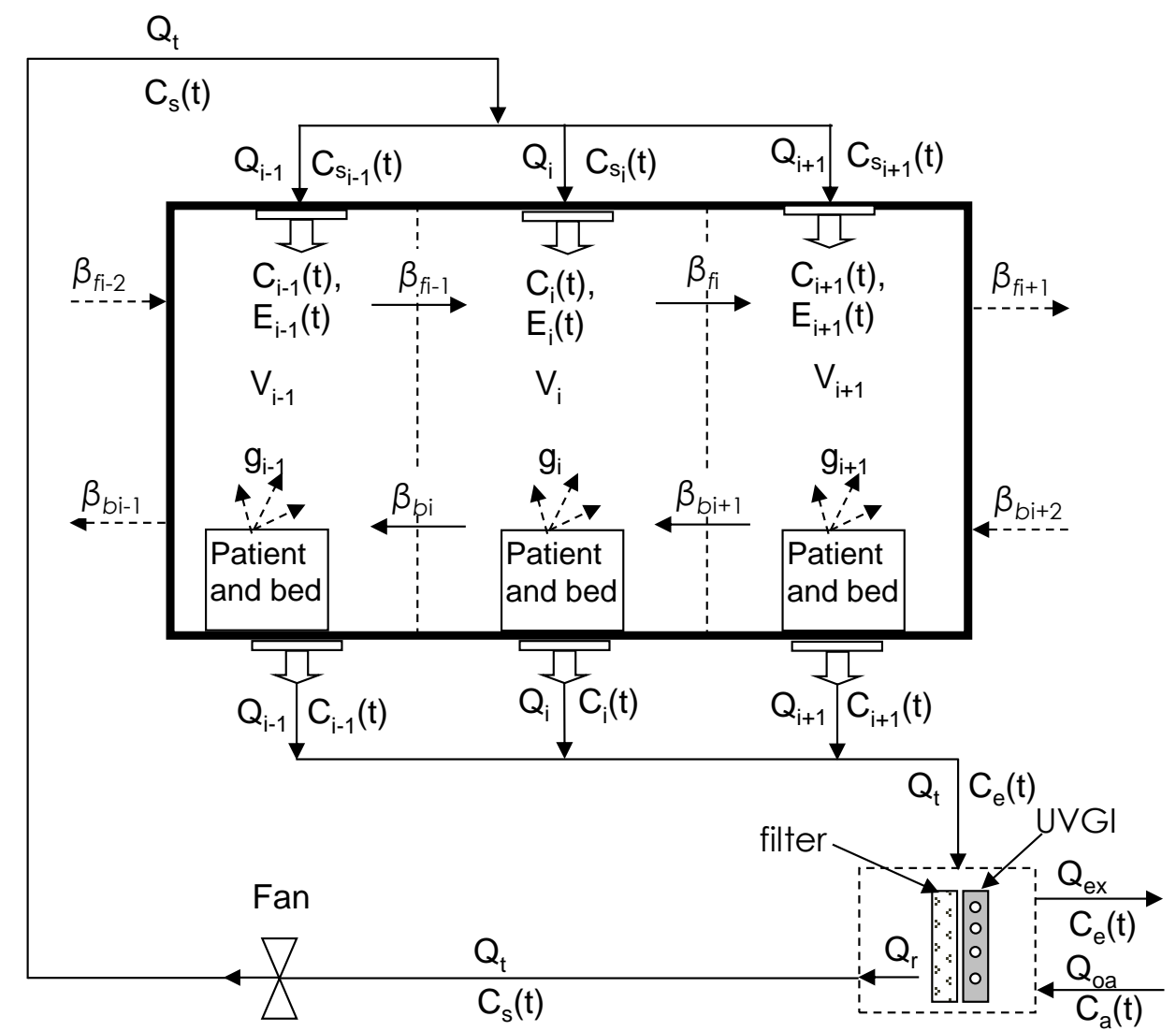

Fig. 4. Schematic representation of the sequential box model for effective air hygiene system model in multi-bed patient ward

As shown in Fig. 4, the patient ward air hygiene system involves a recirculatory system with a single air handling unit (AHU). Return air from the ward enters the AHU, which exhausts some of the air at $Q_{e x}\left(\mathrm{~m}^{3} / \mathrm{s}\right)$ flow rates. At the same time the outdoor air, $Q_{o a}\left(\mathrm{~m}^{3} / \mathrm{s}\right)$, enters the AHU where it is combined with the recirculated air, $Q_{r}\left(\mathrm{~m}^{3} / \mathrm{s}\right)$. The resulting mixed air with a flow rate $Q_{t}\left(\mathrm{~m}^{3} / \mathrm{s}\right)$ passes over air filtration and air disinfection systems with penetration rates, $P_{f}$ and pathogen survival rates, $S_{U V}$ respectively. The cleaned and disinfected air enters the ward at a supply rates equals to the total air flow rates, $Q_{t}\left(\mathrm{~m}^{3} / \mathrm{s}\right)$. For the sequential zones, the total air flow is divided uniformly across the zones. Thus, the supply air enters each zone at a flow rate $Q_{i}\left(\mathrm{~m}^{3} / \mathrm{s}\right)$, where it interacts with the zone air and the emitted pathogen in the zones. 
Each sequential zone is treated as uniformly mixed $[6,10,18]$ with volume $V_{i}\left(\mathrm{~m}^{3}\right)$, emission source strength $g_{i}(t)(\mathrm{pfu} / \mathrm{h}$ or $\mathrm{cfu} / \mathrm{h})$, pathogen concentration, $C_{i}(t)\left(\mathrm{pfu} / \mathrm{m}^{3}\right.$ or cfu $\left./ \mathrm{m}^{3}\right)$, and inhalation exposure concentration, $E_{i}(t)\left(\mathrm{pfu} / \mathrm{m}^{3}\right.$ or $\left.\mathrm{cfu} / \mathrm{m}^{3}\right)$ that is computed as the timeweighted average of the pathogen concentration, $C_{i}(t)$ [52]. The model also contains a series of flow parameters between zones, that is, the forward, $\beta_{f i}$ and backward, $\beta_{b i}$ inter-zonal airflow rates, which are measured in the same units as air flow rates. As spatial uniformity is assumed in each zone, $C_{e}(t)$, the pathogen concentration in the return air equals the sum of concentrations in each of the zones. The extract airflow is similar to the supply flow rate $Q_{i}\left(\mathrm{~m}^{3} / \mathrm{s}\right)$. The return air passes through the air-handling system where the air recirculation cycle continues. The emission source strength, $g_{i}(t)$, adopted in this study is based on quanta infective concentration (QiC), a new metric proposed in a recent study [23]. The QiC is selected for influenza pathogen from previous epidemiological outbreak dataset. As QiC is based on Wells [3] quantum of infection, possible pathogen loss is assumed to be incorporated [53], hence loss factors were excluded.

Unlike the conventional approach, where the outdoor airflow rates is specified as a fraction of the total airflow (about 15-25\% for most buildings [54]), ASHRAE S170-2017 [37] provides minimum outside and total airflow for various spaces, which according to Barrick et al. [55], provides a more reasonable outdoor airflow rates in healthcare facilities. Also, in addition to the provisions for the airflow rates, ASHRAE S170-2017 [37] specifies the use of a filter with minimum efficiency reporting value (MERV) of 6.0 (i.e., MERV 6 filter) in hospital spaces where recirculation is permitted such as patient wards. However, the provisions of ASHRAE S170-2017 [37] does not include air distribution. As air distribution greatly influenced contaminant dispersal and human exposure [56], this study examines the inhalation exposure potentials in the selected ward with - mixing ventilation (MV) and stratum ventilation (SV) systems under ASHRAE baseline requirements.

\subsubsection{Mathematical model formulation}

Equations (3) to (7) show the generic formulation of SBM in the patient ward with air recirculation. The model is used to estimate the spatial and temporal distribution of pathogen as well as inhalation exposure concentrations, which is in turn used to assess the performance of various combinations of air hygiene system parameters. 


$$
\begin{aligned}
& \frac{d C_{i}(t)}{d t}=g_{i}+Q_{i} C s_{i}(t)+\beta_{f i-1} C_{i-1}(t)+\beta_{b i+1} C_{i+1}(t)-\left(\beta_{b i}+\beta_{f i}-Q_{i}\right) C_{i}(t) \\
& C s_{i}(t)=\frac{S_{U V} * P_{f}}{Q_{t}}\left[\left(Q_{o a} * C_{a}(t)\right)+\left(Q_{r} * C_{e}(t)\right)\right] \\
& C_{e}(t)=\frac{1}{Q_{t}} \sum_{i=1}^{n} Q_{i} C_{i}(t) \\
& E_{i}(t)=\frac{p_{s}}{t} \int_{0}^{t} C_{i}(t) \\
& S_{U V}=\exp \left(-k I t_{\exp }\right)
\end{aligned}
$$

Where:

$C_{i}(t)=$ temporal airborne pathogen concentration in the zone $i\left(\mathrm{pfu} / \mathrm{m}^{3}\right.$ or $\left.\mathrm{cfu} / \mathrm{m}^{3}\right)$;

$E_{i}(t)=$ temporal inhalation exposure concentration to airborne pathogen in the zone $i$ $\left(\mathrm{pfu} / \mathrm{m}^{3}\right.$ or $\left.\mathrm{cfu} / \mathrm{m}^{3}\right)$;

$C s(t)=$ temporal airborne pathogen concentration in the supply air $\left(\mathrm{pfu} / \mathrm{m}^{3}\right.$ or $\left.\mathrm{cfu} / \mathrm{m}^{3}\right)$;

$C_{e}(t)=$ temporal airborne pathogen concentration in the exit air $\left(\mathrm{pfu} / \mathrm{m}^{3}\right.$ or $\left.\mathrm{cfu} / \mathrm{m}^{3}\right)$;

$C_{a}(t)=$ temporal airborne pathogen concentration in the outdoor air $\left(\mathrm{pfu} / \mathrm{m}^{3}\right.$ or $\left.\mathrm{cfu} / \mathrm{m}^{3}\right)$;

$t=$ exposure duration between the infector and susceptibles in the environment $(\mathrm{h})$;

$g_{i}=$ airborne pathogen generation rate $(\mathrm{pfu} / \mathrm{h}$ or $\mathrm{cfu} / \mathrm{h})$;

$Q_{i}=$ supply air flow rates in the zone $i\left(\mathrm{~m}^{3} / \mathrm{h}\right)$;

$Q_{t}=$ total air flow rates $\left(\mathrm{m}^{3} / \mathrm{h}\right)$;

$Q_{o a}=$ outdoor air flow rates $\left(\mathrm{m}^{3} / \mathrm{h}\right)$;

$Q_{r}=$ recirculation air flow rates $\left(\mathrm{m}^{3} / \mathrm{h}\right)$;

$S_{U V}=$ airborne pathogen survival rates from UVGI exposures.

$P_{f}=$ penetration fraction of airborne pathogen through the filter, which is equal to $1-\eta_{f}$; and $\eta_{f}$ is the efficiency of the air filtration device; 
$p_{s}=$ penetration factor of the respiratory protection device used by a susceptible person, which is equal to $1-\eta_{s}$; and $\eta_{s}$ is the efficiency of the protection device;

$k=$ rate constant of UVGI device $\left(\mathrm{cm}^{2} / \mu \mathrm{Ws}\right)$;

$I=$ average intensity of UVGI device $\left(\mu \mathrm{W} / \mathrm{cm}^{2}\right)$;

$t_{\text {exp }}=$ pathogen exposure to UVGI field (s);

$\beta_{f i}$ and $\beta_{b i}$ are forward and backward inter-zonal flow rates $(/ \mathrm{h})$, which depends on the space-related parameters - internal loads, layouts, air distribution systems, location and types of air terminal devices, etc. It the zone air speed $u_{i}(\mathrm{~m} / \mathrm{h})$ is known, the inter-zonal flow rates $\left(\mathrm{m}^{3} / \mathrm{h}\right)$ can be computed as $0.5 A_{i} u_{i}$, where $A_{i}$ is the free surface area between the sequential zones $\left(\mathrm{m}^{2}\right)$.

The free surface area and zonal volumes in near- and far-field zones can be computed [6, 57] as area and volume of a hemisphere whose radius is the length between the source and the breathing zone of exposed susceptible. Available evidences $[9,10,57,58]$ suggest that values of the breathing zone distance vary between $300 \mathrm{~mm}$ and $800 \mathrm{~mm}$. Also, the free surface area and zonal volume can be estimated as area and volume of a cuboid. For example, in their study on airborne inhalation exposure risk assessment in aircraft cabins Gupta et al. [9] defined the near-field as a cubical zone of length $304.8 \mathrm{~mm}$, given a volume of $0.0283 \mathrm{~m}^{3}$.

The SBM described above lacks inclusion of the effects of air distribution systems. A couple of possible ways exist to incorporate the air distribution effects through: (a) effective utilisation of outdoor air and/or (b) the room air distribution. While the later can be measured with room air speed, the former is assessed with air change effectiveness $\left(E_{Z}\right)$. ASHRAE S129 [59] and ASHRAE S62.1 [24] defined an effective (actual) air flow rates $\left(Q_{e f f}\right)$ as a quotient of the designed air flow rates $\left(Q_{\text {des }}\right)$ and air change effectiveness $\left(E_{Z}\right)$. That is:

$Q_{e f f}=Q_{\text {des }} / E_{z}$

Accordingly, $E_{Z}$ is influenced by many factors that include space layouts, air distribution, air flow rates, and room temperature [59]. Hence, the standards [24, 59] recommend the 
need for in-situ determination of $E_{Z}$ in a mock-up of the space under consideration. Thus, once $E_{Z}$ is obtained, the actual air flow rates $\left(Q_{e f f}\right)$ is computed for use in the SBM. Since under the same conditions, $E_{Z}$ may vary with air distribution systems, the effects of air distribution can be easily incorporated. Interestingly, the same mock-up experiments is suitable to determine the uniform mixing conditions (effectiveness coefficient), room air distribution (air speed) and effective utilisation of supply air (air change effectiveness).

\subsubsection{Model input parameters and experimental design}

Table 5 summarises the input parameters for the ASHRAE benchmark case study of air hygiene system performance with sequential box modelling. The parameters are as earlier described. The inter-zonal rates are usually estimated from mean air speed and the free surface area between the sequential zones, with the air speed obtain from intermediate experiments or historical records $[6,10,18]$. An earlier study [28] reported the air speed for the patient mock-up as 0.057 and $0.170 \mathrm{~m} / \mathrm{s}$ for mixing and stratum air distribution respectively. Thus, with a free surface area of $14.64 \mathrm{~m}^{2}$ (See Table 5), the respective interzonal airflow rates under mixing and stratum air distributions are $0.417 \mathrm{~m}^{3} / \mathrm{s}$ and 1.244 $\mathrm{m}^{3} / \mathrm{s}$. As the air change effectiveness is reported to be unity, no further adjustment is required for the air flow rates under each of the air distribution systems.

Table 5 Simulation parameters for ASHRAE benchmark case study of air hygiene system performance with SBM

\begin{tabular}{|c|c|}
\hline Items & Details \\
\hline Zone volumes $\left(\mathrm{m}^{3}\right)$ & 128.304 \\
\hline Zone 1 , Zone 2 , Zone 3 & 7.08 \\
\hline Outdoor air change $(/ \mathrm{h})$ & 2.0 \\
\hline Total air change $(/ \mathrm{h})$ & 4.0 \\
\hline Inter-zonal surface area $\uparrow\left(\mathrm{m}^{2}\right)$ & 15.84 \\
\hline \multicolumn{2}{|l|}{ Space air speed $(\mathrm{m} / \mathrm{s})$} \\
\hline Mixing air distribution & 0.057 \\
\hline Stratum air distribution & 0.170 \\
\hline Pathogen & Influenza \\
\hline Air disinfection parameters & NILL \\
\hline Personal protection equipment efficiency & NILL \\
\hline Air filtration parameter & MERV 6 \\
\hline MERV 6 filtration efficiency $\dagger \dagger$ (influenza) & 0.062 \\
\hline \multicolumn{2}{|l|}{ Source/Exposure reference values } \\
\hline Source location & Zone 1 , Zone 2 or Zone 3 \\
\hline Generation $\left(\mathrm{pfu} / \mathrm{m}^{3}\right)$ & 68.6 \\
\hline
\end{tabular}




\begin{tabular}{lc} 
Threshold $\left(\mathrm{pfu} / \mathrm{m}^{3}\right)$ & 0.0796 \\
\hline Simulation periods $(\mathrm{h})$ & 10 \\
\hline$\dagger$ With the space width of $6.6 \mathrm{~m}$ and space height of $2.4 \mathrm{~m}$; the sequential \\
zone interface area equals $6.6 \mathrm{~m} \times 2.4 \mathrm{~m}=15.84 \mathrm{~m}^{2} ;$ \\
$\dagger \dagger$ Data source: Wladyslaw et al. $[60]$
\end{tabular}

The experimental design and analysis involve the use of Taguchi robust design method $(\mathrm{RDM})$, which is based on the philosophy that product or process performance deviates from intended functions as a result of the effects from uncontrollable conditions. These uncontrollable conditions are termed noise factors. Taguchi RDM approach involves the selection of a suitable quality characteristic $(y)$, a number of design (control) parameters $(x)$, and noise (uncontrollable) factors (z), and appropriate orthogonal array (OA) for the experimental design. As noise factors are uncontrollable, they are imposed on the system to observe their effects on the quality characteristics [46]. The goal is to obtain the optimum settings of the control factors under the influence of the noise factors. The optimum settings of the control factors are termed robust parameters as they are insensitive to the variability caused by the noise conditions.

Based on the ASHRAE S170-2017 [37] specification, the study design involves the controllable factors: air distribution systems (Mixing ventilation, MV and Stratum ventilation, $S V)$, outdoor air change rate $(2 / \mathrm{h})$, total air change rate $(4 / \mathrm{h})$, and air filtration efficiency (-). Also, the study considers the infector location as a noise factor. Table 6 shows the experimental design for the baseline case study. For the cases shown in Table 6 SBM is used to compute the inhalation exposure concentrations at each of the zones. In addition to experimental design techniques, Taguchi robust design methods include a unique data analysis and decision-making tool - the signal-to-noise $(\mathrm{S} / \mathrm{N})$ ratio. As the name implies, the $\mathrm{S} / \mathrm{N}$ ratio measures the rate of signal (controllable conditions) changes with the noise (uncontrollable conditions).

Table 6 Experimental design for the case studies

\begin{tabular}{cllcccc}
\hline Case & & $\begin{array}{l}\text { Air } \\
\text { Distribution }\end{array}$ & $\begin{array}{c}\text { Outdoor air } \\
\text { change }(/ \mathrm{h})\end{array}$ & $\begin{array}{c}\text { Total air } \\
\text { change }(/ \mathrm{h})\end{array}$ & $\begin{array}{c}\text { Filter } \\
\text { efficiency (-) }\end{array}$ & $\begin{array}{c}\text { Infector } \\
\text { location }\end{array}$ \\
\hline 1 & A & MV & 2 & 4 & 0.062 & Zone 1 \\
& B & MV & 2 & 4 & 0.062 & Zone 2 \\
& C & MV & 2 & 4 & 0.062 & Zone 3 \\
2 & A & SV & 2 & 4 & 0.062 & Zone 1
\end{tabular}




\begin{tabular}{llllll} 
B & SV & 2 & 4 & 0.062 & Zone 2 \\
C & SV & 2 & 4 & 0.062 & Zone 3 \\
\hline
\end{tabular}

Thus, the goal is to maximise the $\mathrm{S} / \mathrm{N}$ characteristics, which implies system robustness. Based on the objective of the experiments, the basic S/N ratio types include Nominal-theBest (NTB), Smaller-the-Better (STB), and Larger-the-Better (LTB). With a threshold level (i.e., reference concentration, $\mathrm{RfC}$ ) of pathogen employed in this study, the NTB S/N ratio is adopted. NTB is computed from:

$$
\begin{aligned}
& S / N=10 \log \left(\bar{y}^{2} / S^{2}\right) \\
& \bar{y}=\frac{1}{n} \sum_{i=1}^{n} y_{i}
\end{aligned}
$$

Where $y_{i}, \bar{y}$, and $S$ are respectively the observed quality characteristics (i.e., inhalation exposure concentration), its mean and variance for each experimental trials, $i$.

\subsection{Using deSolve (solver) package for Sequential Box Model}

For both validation and baseline cases, the study computes the spatial and temporal evolution of the concentration with the SBM using deSolve (solver) package [42] in R 3.4.2 [43] environment. $\mathrm{R}$ is an open-source statistical programming language and environment that has widely been used in various quantitative disciplines [61]. In addition to being opensource, R-programming provides an astonishing computational efficient environment when compared to other standard programs [61]. $\mathrm{R}$ is beneficial in that it provides more flexible and interactive implementation, better readability of the code, and access to R's high-level procedures [42].

Additionally, a major benefit of $\mathrm{R}$ is that various users across the globe freely contribute to the $\mathrm{R}$ project by developing packages (solvers) to the users' community. A package in $\mathrm{R}$ refers to a set of functions to execute specialised routines targeted at solving a set of problems. Numerous packages exist for varying fields of science, engineering, medicine, social science, etc.; and are freely available in the public domain that is maintained by the Comprehensive R Archival Network (CRAN) [43]. The deSolve solver is an R package [42] for solving state-space problems, that is, initial value problems (IVP) for ordinary differential equations (ODE), differential algebraic equations (DAE), and partial differential 
equations (PDE). Also, the solver is capable of handling dynamic parameters (such as generation rate, inlet concentration, airflow rates, and loss functions). Thus, having the capability for dynamic modelling of IVP with several thousands of state variables [42], the solver provides an efficient method for state-space model development and applications. Details of its syntax for solving IVP is available in many science and engineering texts [61, 62]. The procedure for implementing the SBM in R follows the method described in Appendix A.

\section{Results and Discussions}

This study carries out sub-configuration validation of sequential box model with an opensource solver, using data from existing studies [13, 19, 21, 45]. The data were selected to cover dilution ventilation and filtration [45], hospital wards airborne infection risk [13], performance of upper-air UVGI in ventilated rooms [19], and transient pathogen concentration decay with air disinfection [21]. The validated model is used in the case studies of air hygiene system performance, for controlling exposure to influenza contagion, under ASHRAE S170-2017 [37] specifications. In the case studies, robust design method was employed to assess the performance of air hygiene system design (control) parameters under the influence of noise (uncontrollable) conditions. While the control factors are dilution ventilation, air change rates, and air filtration; infector location is the noise factor. The control and noise factors with their considered settings in this study are as shown in Table 6. The quality characteristics selected in this study is exposure concentration. Although many metrics exist on assessing air quality for exposure and/or infection control, all of them are dependent on the exposure concentration. Hence, the choice of exposure concentration appears plausible. Data for the experimental trials were obtained from numerical simulation with the validated SBM.

\subsection{Model validation}

Figs. 5 to 7 present the results of SBM sub-configuration validation with the selected existing studies [13, 19, 21, 45]. Comparing the SBM and the Mumma [45] validation results, Fig. 5 shows the transient concentration evolution under the DOAS and VAV system. It should be noted that the results in Fig. 5 are presented as dimensionless quantity normalised by the peak concentration of DOAS at zero filtration efficiency. The results 
Building and Environment

Volume 161, 15 August 2019, 106241

revealed a close match between the SBM and data from the original study, thereby suggesting the suitability of the numerical solver for SBM. 


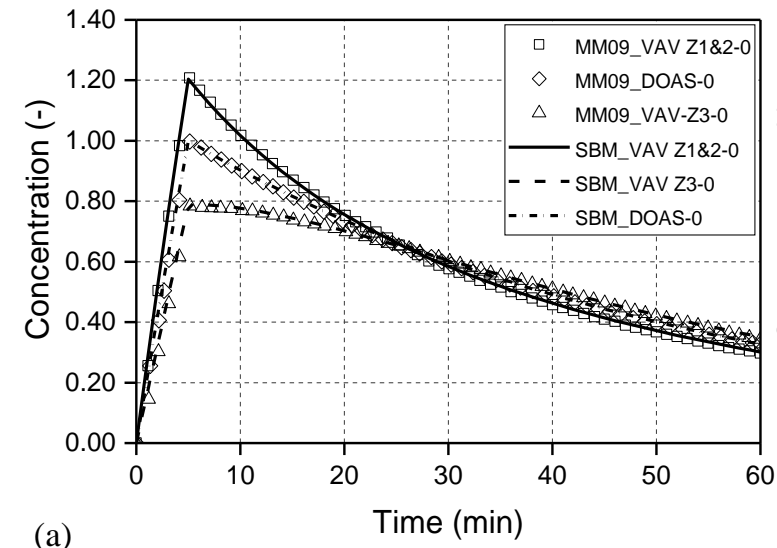

(a)

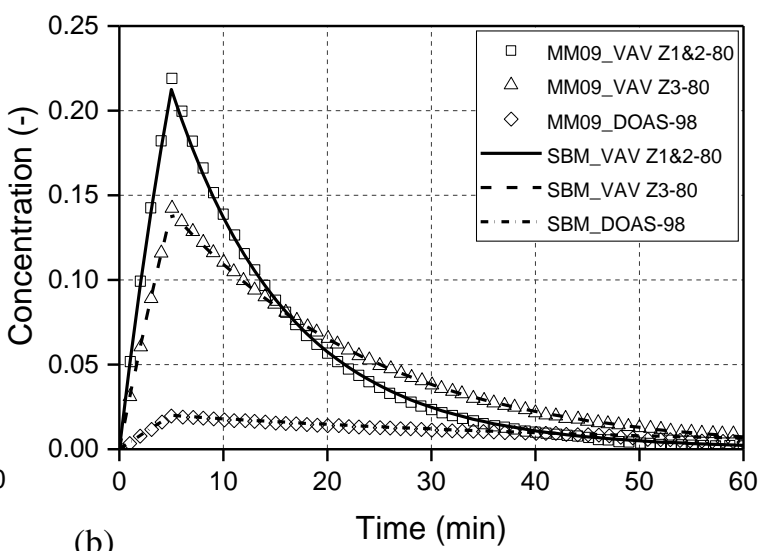

(b)

Fig. 5. Model validation results of comparing transient concentration with: (a) filter efficiencies of $0 \%$ in VAV and DOAS, and (b) VAV filters efficiency of $80 \%$ and DOAS filter efficiency of 98\%. (MM09: Mumma (2009) [45] data and SBM: sequential box model simulation results).

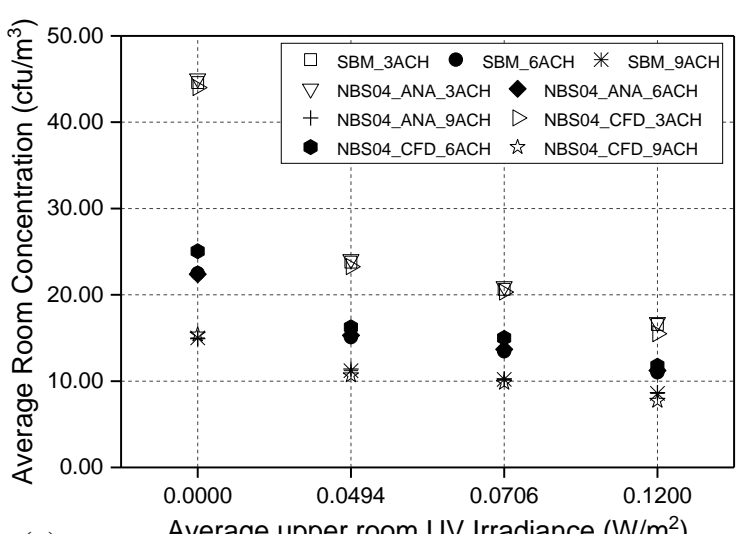

(a)

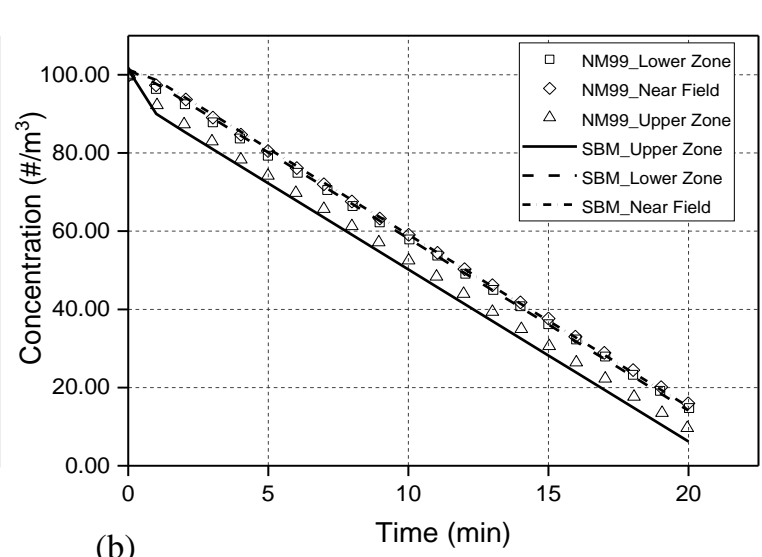

(b)

Fig. 6. Model validation results of comparing: (a) average room pathogen concentration under different $\mathrm{ACH}$, and (b) spatial and transient pathogen concentration decay, in rooms with upper air ultraviolet irradiation systems. Notes: (NBS04: Noakes, Beggs and Sleigh (2004) [19] data, NM99: Nicas and Miller (1999) [21], ANA: Analytical, CFD: Computational Fluid Dynamics, and SBM: sequential box model simulation results)

Fig. 6a compares the SBM predictions of average room pathogen concentrations with data from Noakes et al. [19]. Generally, under different air change rates and UV irradiance, the results of SBM compare well with that of CFD and analytical methods from the original study. Fig. 6b shows, for both SBM and the data from Nicas et al. [21], the transient pathogen decay due to the effects of upper-air UVGI. As shown, there is a relative correlation in the results of SBM and the primary study for all the zones. These findings 
suggest the suitability of the numerical solver for SBM of pollutant profile under the influence of upper air UVGI.

Results shown in Fig. 7 are the transient number of new infection cases in the simulated room by Noakes et al. [13]. The shaded boundaries in Fig. 7 indicate 1.0 standard deviation from the mean infection cases. As shown, there are some slight differences in the SBM results and the validation study, which may be due to the steady state assumption in the original study. Unlike the approach of Noakes et al. [13], SBM is free of steady-state assumptions. Regardless of the slight differences in both simulated cases, the overlapping boundaries of variabilities in both predictions suggest that SBM closely predict similar infections with the original study.

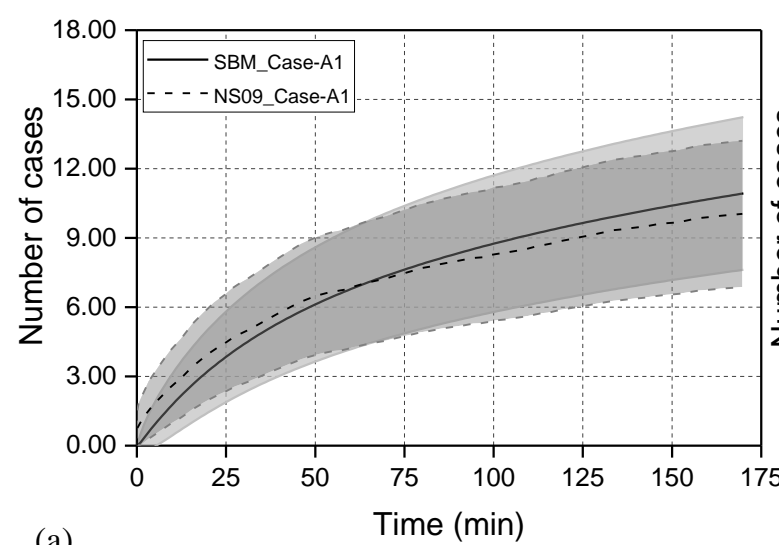

(a)

Fig. 7. Model validation of the total infection in multi-bed patient ward at an inter-zonal airflow rate of: (a) $9 \mathrm{~m}^{3} / \mathrm{min}$, and (b) $27 \mathrm{~m}^{3} / \mathrm{min}$. Note: The shaded boundaries indicate error bars of 1.0 s.d. from the mean values. (NS09: Noakes and Sleigh (2009) data, SBM: sequential box model simulation results, and Case A represents the selected settings from NSO9).

Overall, the validation results indicate that the SBM formulation, the numerical solver, and the investigator were able to produce a reasonable agreement with previously documented data. The sub-configuration validation dataset varies among dilution ventilation (dedicated outdoor air system and variable air volume system), air filtration system, and upper air disinfection system. Hence, one can conclude that the researchers are capable of using SBM and the numerical solver to satisfactorily model and simulate cases involving indoor air exposure assessments. 


\subsection{Inhalation exposure assessment: ASHRAE S170 (2017) baseline conditions}

Fig. 8 compares the inhalation exposure concentration level for MV and SV systems under ASHRAE S170-2017 baseline conditions. For both MV and SV cases, the result shows the influence of near emission source effects on the inhalation exposure concentration. When the infector is in zone 1, the exposure near the infector (Z1N1) exceeds those under the farfield zones (Z2N1 and Z3N1). The results also indicate that concentration gradients exist within each zone. For example, considering the infector at Zone 1, the exposure level at Z1N1 (infector location) exceeds that of Zone 2 (Z2N1), which in turn exceeds Zone 3 (Z3N1).

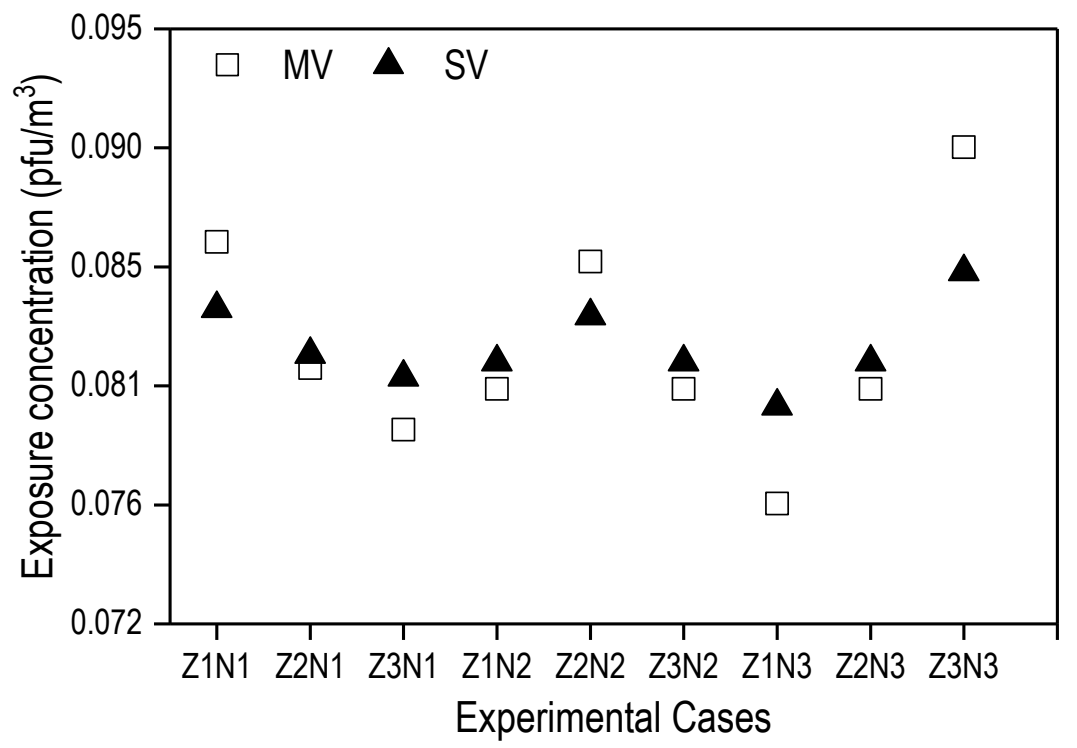

Fig. 8. Inhalation exposure concentration levels for mixing and stratum air ventilation under ASHRAE S170 (2013) baseline conditions. Notes: (N: infector locations, Z: Zones, 1, 2, 3 are location identifiers).

The results are similar when the infector is in Zones 2 and 3. The exposure levels when the infector is in zone 3 is a reversal (as expected) of Zone 1, with Zone 3 (Z3N3, infector location) having highest exposure level, followed by Zone 2 (Z2N3), and Zone 1 (Z1N3) in that order. When the infector is in Zone 2 (Z2N2), the exposure levels at Zones 1 (Z1N2) and 3 (Z3N2) are approximately the same. Comparing between MV and SV, the exposure under MV (open squares) appears lower than that under SV (filled triangles) in some instances. Regardless, exposure levels under SV are less dispersed than that under MV, thereby suggesting higher robustness (as will be shown later). 
There are two significant findings from these results. Firstly, although a uniformly-mixed condition is assumed in the formulation of SBM for each of the zones, there are concentration gradients in the zones that vary between the highest in the near-source proximate zones and the smallest in the far-field zones. Thus, the well-mixed assumption does not necessarily imply equal exposure to contaminants. The assumption is a simplification for solving the mass-balance equation as well as characterising air distribution systems [7]. Therefore, while the notion that using the one-box modelling approach for exposure assessment may under-predict near-field exposure intensity, assuming a well-mixed condition may not do so in SBM. Secondly, comparing inhalation exposure under ASHRAE S170-2017 [37] baseline conditions, SV provides a less variable concentration than MV. This result suggests that SV can be used for robust control of inhalation exposure. Since exposure precedes infection, SV possesses a potential for controlling infection risks.

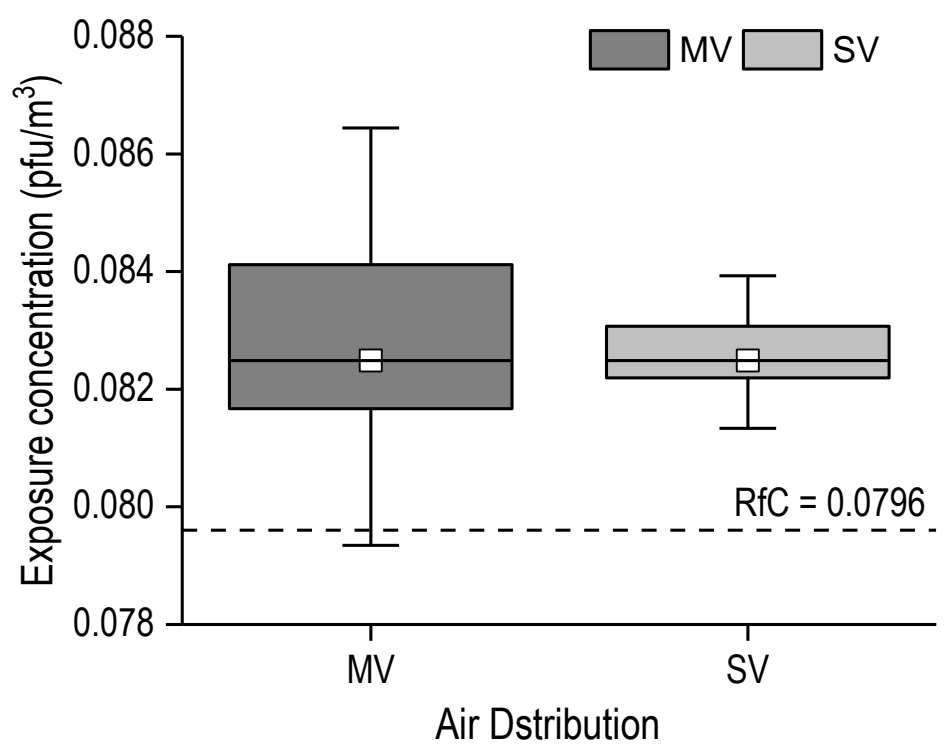

Fig 9. Exposure concentration summary for mixing and stratum ventilation under ASHRAE 170 (2013) baseline condition (Outdoor air change rate $=2$ per hour, total air change rates $=4$ per hour, filtration is MERV 6).

The previous results (Fig. 8) explain the spatial distribution of inhalation exposure concentration between the patient ward zones together with near-proximate effects on exposure potentials. However, the information on the protective nature of the ward environment under ASHRAE S170-2017 [37] baseline condition is still unclear. Fig. 9 further compares the inhalation exposure concentration for MV and MV under ASHRAE 
S170-2017 [37] baseline conditions. In Fig. 9, the horizontal lines within the rectangles indicate the mean inhalation exposure concentration while the bars represent the standard deviation. Also, the dotted horizontal line indicate the reference concentration $(\mathrm{RfC}=$ $0.0796 \mathrm{pfu} / \mathrm{m}^{3}$ ) of influenza droplet nuclei [23]. The results show that under ASHRAE S170-2017 [37] baseline conditions, with the influence of noise factors of infector locations, the average inhalation exposure concentration for both MV and SV are similar at about $0.0825 \mathrm{pfu} / \mathrm{m}^{3}$. The results of similarities in the mean exposure concentration follow the earlier findings that both systems provide a uniformly mixed condition with an effectiveness coefficient of unity [28]. However, under both MV and SV, the inhalation exposure concentration exceeds the reference concentration of $0.0796 \mathrm{pfu} / \mathrm{m}^{3}$ for influenza contagion. With such an increase in the inhalation exposure over the reference concentration, the ASHRAE baseline conditions may be insufficient to protect susceptible occupants against exposure to influenza contagion.

Table 7 Summary of robustness analysis

\begin{tabular}{llccc}
\hline Cases & Air distribution & Mean $\left(\mathrm{pfu} / \mathrm{m}^{3}\right)$ & $\mathrm{SD}\left(\mathrm{pfu} / \mathrm{m}^{3}\right)$ & S/N Ratio $(\mathrm{dB})$ \\
\hline 1 & Mixing & 0.0825 & 0.0041 & 26.0 \\
2 & Stratum & 0.0825 & 0.0015 & 34.6 \\
\hline
\end{tabular}

Table 7 summarises the robustness analysis for the case studies. As shown in Table 7, the variability in inhalation exposure concentration (also shown by the bar in Fig. 9) with SV is about three-fold lower than that of MV. As smaller variation is a desirable characteristic for system robustness, the resulting $\mathrm{S} / \mathrm{N}$ ratio for $\mathrm{SV}(34.6 \mathrm{~dB})$ is larger than that of $\mathrm{MV}(26$ dB). High system robustness requires a large signal and small noise, the results thus suggest that under similar conditions, SV provides a more robust air hygiene systems than MV. The results imply that SV provides a more stable environment for controlling inhalation exposure.

Further comparison of the system robustness between the two systems revealed that there is a difference of about $9 \mathrm{~dB}(35-26=9 \mathrm{~dB})$ between SV and MV. In Taguchi quality engineering, a 3-decibel increase in the $\mathrm{S} / \mathrm{N}$ ratio between two options is equivalent to a 50 per cent reduction in quality cost and/or improvement in performance characteristics [63, 64], inhalation exposure concentration in this case. Thus, SV provides an opportunity to improve indoor air quality (or reduce associated costs) by $150 \%$ over MV. This result is 
consistent with findings from an earlier study [28], which reported that SV provides a potential to improve airflow characteristics by the same amount.

These findings revealed that despite similar average exposure concentration, SV has a potential for higher robustness (insensitivity to variability sources) in air quality provision than the MV even at the same settings of air hygiene systems. By comparing both MV and $\mathrm{SV}$ against the reference concentration, it is revealed that there is high inhalation exposure potential to influenza pathogen under the ASHRAE S170-2017 [37] baseline conditions. From the foregoing, since at reference concentration of $0.0796 \mathrm{pfu} / \mathrm{m}^{3}$, the provision of ASHRAE S170-2017 [37] baseline air hygiene system condition is insufficient for insuring exposed occupants, then two conclusions are possible: (a) that the reference concentration (RfC) at $10 \%$ benchmark response $[27,65]$ appears adequate to design air hygiene system (see Oladokun [23] for more details). Although RfC at 5\% benchmark reference will provide a more protective condition, such a decision will further indicate the inability of ASHRAE S170-2017 baseline conditions to operate the environment at the RfC; and (b) that ASHRAE S170-2017 [37] baseline conditions for patient ward with room air recirculation may provide ineffective air hygiene system to protect occupants (patients, caregivers and visitors) against excessive inhalation exposure. Therefore, it can be concluded that using a combination of robust design method with quanta infective concentration (QiC) and reference concentration (RfC) provide improved insights into potential inhalation exposure potential under a varying combination of air hygiene systems. Also, as the inhalation exposure concentration exceeds the RfC under the tested air distribution, dilution ventilation airflow, and air cleaning, there is a need for improved air hygiene system design for controlling inhalation exposure in the patient ward with air recirculation.

\section{Conclusion}

The sequential box model (SBM) for exposure assessment was validated using a numerical solver in the R open-source statistical programming environment. The validated model was used to assess inhalation exposure to influenza contagion in a multi-bed patient ward, with ASHRAE S170-2017 baseline specification of design parameters, under the effects of uncontrollable infector location factor. The combination of controllable design parameters (air distribution, mixing and stratum ventilation; outdoor airflow at $2 \mathrm{ACH}$; total airflow at $4 \mathrm{ACH}$; and air filtration of MERV 6) and uncontrollable infector location factor was 
executed using Taguchi robust design method. The validation results indicated that the open-source numerical solver could closely simulate the sequential box model of indoor contaminant dispersal, air disinfection, and exposure risk assessments.

The case study results revealed a similar average inhalation exposure concentration of $0.0825 \mathrm{pfu} / \mathrm{m}^{3}$ under both mixing ventilation and stratum ventilation. In terms of robustness, the results showed that regardless of the similar average inhalation exposure, stratum ventilation is three-fold insensitive to the variability in exposure than mixing ventilation. The robustness advantage of SV over MV was further confirmed with a $9 \mathrm{~dB}$ increase of Taguchi $\mathrm{S} / \mathrm{N}$ ratio in $\mathrm{SV}$ over $\mathrm{MV}$; the $\mathrm{S} / \mathrm{N}$ increase suggests a potential for air quality improvement or air quality cost reduction by up to $150 \%$. Further, findings also indicated that under both air distribution systems, the average inhalation exposure exceeds the influenza reference concentration of $0.0796 \mathrm{pfu} / \mathrm{m}^{3}$. This indicates that under the ASHRAE S170-2017 baseline condition, there is an increase of about $4 \%$ in the inhalation exposure over the reference concentration. Therefore, the ASHRAE S170-2017 baseline conditions may be insufficient to protect susceptible occupants against inhalation exposure to influenza contagion. Hence a more protective design of air hygiene system parameters is recommended for inhalation exposure control in a patient ward with air recirculation against airborne contagion such as influenza.

The work presented in this study forms part of a wider research project on effective air hygiene system design for controlling exposure to airborne contagion in healthcare facilities. More work is being carried out on other mechanisms, including the varying pulmonary activities (constant and transient breathing, speaking, coughing, etc.), varying combination of dilution ventilation, air cleaning, air disinfection, and personal protection. Future work will optimise the air hygiene system parameter design (including air recirculation effects) by combining ASHRAE S170-2017 specifications with air disinfection and personal protective equipment, under the influence of uncontrollable infector location factor. The resulting exposure concentration will be benchmarked against the reference concentration. As the case study presented in this study is limited to influenza, future work will consider Mycobacterium Tuberculosis and other contagions with the doseresponse dataset for developing QiC and RfC. 


\section{Acknowledgements}

The work described in this paper is supported by a General Research Grant from the Research Grants Council of the Hong Kong Special Administrative Region, China (Project No. CityU 11210617).

\section{References}

[1] N.E. Klepeis, W.C. Nelson, W.R. Ott, J.P. Robinson, A.M. Tsang, P. Switzer, et al. The National Human Activity Pattern Survey (NHAPS): a resource for assessing exposure to environmental pollutants. J. Exposure Anal. Environ. Epidemiol. 2001;11(3):231-252.

[2] K. Sexton, M.A. Callahan, E.F. Bryan. Estimating exposure and dose to characterize health risks: the role of human tissue monitoring in exposure assessment. Environ. Health Perspect. 1995;103(Suppl 3):13-29.

[3] W.F. Wells. Airborne Contagion and Air Hygiene. An Ecological Study of Droplet Infections. Cambridge, MA: Harvard University Press; 1955.

[4] Q. Chen. Ventilation performance prediction for buildings: A method overview and recent applications. Build. Environ. 2009;44(4):848-858.

[5] Q. Chen, K. Lee, S. Mazumdar, S. Poussou, L. Wang, M. Wang, et al. Ventilation performance prediction for buildings: model assessment. Build. Environ. 2010;45(2):295-303.

[6] AIHA. Mathematical models for estimating occupational exposure to chemicals. Fairfax, VA: AIHA Press; 2000.

[7] R.J. Heinsohn, J.M. Cimbala. Indoor air quality engineering: environmental health and control of indoor pollutants. USA: Marcel Dekker; 2003.

[8] P.V. Nielsen, F. Allard, H.B. Awbi, L. Davidson, A. Schälin. Computational Fluid Dynamics in Ventilation Design. In: Nielsen P.V., editor. REHVA Guidebook. Finland: REHVA; 2007.

[9] J.K. Gupta, C.H. Lin, Q. Chen. Inhalation of expiratory droplets in aircraft cabins. Indoor Air. 2011;21(4):341-350. doi: 10.1111/j.1600-0668.2011.00709.x

[10] E.J. Furtaw, M.D. Pandian, D.R. Nelson, J.V. Behar. Modeling Indoor Air Concentrations Near Emission Sources in Imperfectly Mixed Rooms. J. Air Waste Manage. Assoc. 1996;46(9):861-868. doi: 10.1080/10473289.1996.10467522

[11] C.B. Beggs, C.J. Noakes, P.A. Sleigh, L.A. Fletcher, K. Siddiqi. The transmission of tuberculosis in confined spaces: an analytical review of alternative epidemiological models. Int. J. Tuberc. Lung Dis. 2003;7(11):1015-1026. 
[12] M. Nicas, T.W. Armstrong. Using a Spreadsheet to Compute Contaminant Exposure Concentrations Given a Variable Emission Rate. AIHA J. 2003;64(3):368-375. doi: $10.1080 / 15428110308984829$

[13] C.J. Noakes, P.A. Sleigh. Mathematical models for assessing the role of airflow on the risk of airborne infection in hospital wards. J. R. Soc. Interface. 2009;6(SUPPL. 6):S791-S800. doi: 10.1098/rsif.2009.0305.focus

[14] E. Riley, G. Murphy, R. Riley. Airborne spread of measles in a suburban elementary school. Am. J. Epidemiol. 1978;107(5):421 - 432.

[15] L. Gammaitoni, M.C. Nucci. Using a mathematical model to evaluate the efficacy of TB control measures. Emerging Infect. Dis. 1997;3(3):335-342.

[16] W.W. Nazaroff, M. Nicas, S.L. Miller. Framework for Evaluating Measures to Control Nosocomial Tuberculosis Transmission. Indoor Air. 1998;8(4):205-218. doi: 10.1111/j.1600-0668.1998.00002.x

[17] C.B. Beggs, S.J. Shepherd, K.G. Kerr. Potential for airborne transmission of infection in the waiting areas of healthcare premises: stochastic analysis using a Monte Carlo model. BMC Infect. Dis. 2010;10(1):247. doi: 10.1186/1471-2334-10247

[18] P.B. Ryan, J.D. Spengler, P.F. Halfpenny. Sequential box models for indoor air quality: Application to airliner cabin air quality. Atmos. Environ. 1988;22(6):10311038. doi: http://dx.doi.org/10.1016/0004-6981(88)90333-2

[19] C.J. Noakes, C.B. Beggs, P.A. Sleigh. Modelling the Performance of Upper Room Ultraviolet Germicidal Irradiation Devices in Ventilated Rooms: Comparison of Analytical and CFD Methods. Indoor Built Environ. 2004;13(6):477-488. doi: $10.1177 / 1420326 \times 04049343$

[20] B.G. Wagner, B.J. Coburn, S. Blower. Calculating the potential for within-flight transmission of influenza A (H1N1). BMC Med. 2009;7(1):81. doi: 10.1186/17417015-7-81

[21] M. Nicas, S.L. Miller. A Multi-Zone Model Evaluation of the Efficacy of UpperRoom Air Ultraviolet Germicidal Irradiation. Appl. Occup. Environ. Hyg. 1999;14(5):317-328. doi: 10.1080/104732299302909

[22] S.N. Rudnick, D.K. Milton. Risk of indoor airborne infection transmission estimated from carbon dioxide concentration. Indoor Air. 2003;13(3):237-245. doi: 10.1034/j.1600-0668.2003.00189.x

[23] M.O. Oladokun. Effective Air Hygiene System Design for Airborne Contagion Exposure Control in Health Care Facilities - Experimental and Numerical Studies [PhD Dissertation]. Hong Kong: City University of Hong Kong; 2018.

[24] ASHRAE. ANSI/ASHRAE standard 62.1-2013: ventilation for acceptable indoor air quality: American Society of Heating, Refrigerating and Air-Conditioning Engineers, Inc.; 2013. 
[25] K.S. Crump. A new method for determining allowable daily intakes. Fundam. Appl. Toxicol. 1984;4(5):854-871. doi: https://doi.org/10.1016/0272-0590(84)90107-6

[26] L.D. Michael, C.H. Richard, H. Rolf, B. Karen. Novel Methods for the Estimation of Acceptable Daily Intake. Toxicol. Ind. Health. 1985;1(4):23-41. doi: 10.1177/074823378500100404

[27] U.S. EPA. Benchmark Dose Technical Guidance. 2012. Retrieved January 22, 2018, from https://www.epa.gov/sites/production/files/201501/documents/benchmark_dose_guidance.pdf.

[28] O. Majeed, L. Zhang. Influence of Air Distribution and Room Pressurisation on Air Velocity and Air-Change Effectiveness in a Bay-Designed Ward with Dedicated Outdoor Air System. Roomvent \& Ventilation 2018, Excellent Indoor Climate and High Performing Ventilation, 2 - 5 June 2018. Espoo Finland2018.

[29] B. Blocken, C. Gualtieri. Ten iterative steps for model development and evaluation applied to Computational Fluid Dynamics for Environmental Fluid Mechanics. Environ. Model. Software. 2012;33:1-22. doi: http://dx.doi.org/10.1016/j.envsoft.2012.02.001

[30] J.H. Ferziger, M. Peric. Computational methods for fluid dynamics. Berlin, Germany: Springer-Verlag; 2002.

[31] T. van Hooff, V. Nielsen Peter, Y. Li. CFD Predictions of Non-Isothermal Ventilation Flow - How Can the User Factor be Minimised? Indoor Air. 2018;0(ja). doi: 10.1111/ina.12492

[32] L. Peng, P.V. Nielsen, X. Wang, S. Sadrizadeh, L. Liu, Y. Li. Possible userdependent CFD predictions of transitional flow in building ventilation. Build. Environ. 2016;99:130-141. doi: http://dx.doi.org/10.1016/j.buildenv.2016.01.014

[33] B. Blocken. 50 years of Computational Wind Engineering: Past, present and future. J. Wind. Eng. Ind. Aerod. 2014;129:69-102. doi: http://dx.doi.org/10.1016/j.jweia.2014.03.008

[34] Z. Lin, T.T. Chow, C.F. Tsang. Validation of a CFD Model for Research into Stratum Ventilation. Int. J. Vent. 2006;5(3):345-364. doi: doi:10.5555/ijov.2006.5.3.345

[35] Z. Lin, T.T. Chow, C.F. Tsang, K.F. Fong, L.S. Chan. Stratum ventilation - A potential solution to elevated indoor temperatures. Build. Environ. 2009;44(11):2256-2269. doi: 10.1016/j.buildenv.2009.03.007

[36] B. Blocken, W.D. Janssen, T. van Hooff. CFD simulation for pedestrian wind comfort and wind safety in urban areas: General decision framework and case study for the Eindhoven University campus. Environ. Model. Software. 2012;30:15-34. doi: http://dx.doi.org/10.1016/j.envsoft.2011.11.009

[37] ASHRAE. ANSI/ASHRAE/ASHE Standard 170-2017: Ventilation Standard For Health Care Facilities. Atlanta: American Society of Heating, Refrigerating and AirConditioning Engineers.; 2017. 
[38] CDC. Guidelines for preventing transmission of Mycobacterium tuberculosis in health-care settings. Morbidity Mortality Weekly Report 43 (RR-13). DHHS 2005.

[39] Department of Health/Estates and Facilities Division. Health Technical Memorandum 03-01: Specialised ventilation for healthcare premises. Part A Design and installation. Norwich: The Stationary Office; 2007.

[40] E. Cubi Montanya, J. Salom Tormo, N. Garrido Soriano. Energy-efficient ventilation control strategies for surgery rooms. Sci. Technol. Built. En. 2015;21(2):228-237. doi: $10.1080 / 23744731.2014 .992708$

[41] E. Cubi Montanya, J. Salom Tormo, N. Garrido Soriano. Indoor environmental quality and infection control in surgery rooms: Code requirements vs. performance motivation. A critical review. HVAC\&R Res. 2014;20(6):643-654. doi: 10.1080/10789669.2014.929423

[42] S. Karline, P. Thomas, R.S. Woodrow. Solving Differential Equations in R: Package deSolve. J. Stat. Softw. 2010;33(9):1-25. doi: 10.18637/jss.v033.i09

[43] R. Core Team. R: A Language and Environment for Statistical Computing. Vienna, Austria: R Foundation for Statistical Computing; 2017.

[44] K. Soetaert, F. Meysman. Reactive transport in aquatic ecosystems: Rapid model prototyping in the open source software R. Environ. Model. Software. 2012;32:4960. doi: http://dx.doi.org/10.1016/j.envsoft.2011.08.011

[45] S.A. Mumma. Contaminant Transport and Filtration Issues with DOAS. ASHRAE Trans. 2009;115(2):350-357.

[46] M.S. Phadke. Quality engineering using robust design. Englewood Cliffs, NJ: Prentice Hall; 1989.

[47] G. Ko, K.M. Thompson, E.A. Nardell. Estimation of Tuberculosis Risk on a Commercial Airliner. Risk Anal. 2004;24(2):379-388. doi: 10.1111/j.02724332.2004.00439.x

[48] A.R. Escombe, D.A.J. Moore, R.H. Gilman, M. Navincopa, E. Ticona, B. Mitchell, et al. Upper-Room Ultraviolet Light and Negative Air Ionization to Prevent Tuberculosis Transmission. PLOS Med. 2009;6(3):e1000043. doi: 10.1371/journal.pmed.1000043

[49] Department of Health. Health Building Note 04-01 - Adult in-patient facilities. Department of Health; 2013.

[50] D. Müller, C. Kandzia, R. Kosonen, A.K. Melikov, P.V. Nielsen. Mixing Ventilation-Guide on mixing air distribution design, REHVA Guidebook No 19. In: Müller D., editor. REHVA Guidebook. Brussels: RHEVA; 2013.

[51] S. Zhang, Y. Cheng, M.O. Oladokun, Z. Lin. Subzone control method of stratum ventilation for thermal comfort improvement. Build. Environ. 2019;149:39-47. doi: https://doi.org/10.1016/j.buildenv.2018.11.041 
[52] G. Ramachandran. Framework for Occupational Exposure Assessment. Occupational Exposure Assessment for Air Contaminants: CRC Press; 2005. p. 312.

[53] E.A. Nardell. Wells Revisited: Infectious Particles vs. Quanta of Mycobacterium tuberculosis. Mycobac. Dis. 2016;6(5):1-3. doi: 10.4172/2161-1068.1000231

[54] K.J. Wladyslaw. Immune building systems technology: McGraw Hill Professional; 2003.

[55] J.R. Barrick, R.G. Holdway. Mechanical Systems Handbook for Health care Facilities: American Society for Healthcare Engineering; 2014.

[56] D. Rim, A. Novoselac. Ventilation effectiveness as an indicator of occupant exposure to particles from indoor sources. Build. Environ. 2010;45(5):1214-1224. doi: http://dx.doi.org/10.1016/j.buildenv.2009.11.004

[57] D.J. Burton. Hemeon's Plant and Process Ventilation. Lewis Publishers; 1999.

[58] C.E. Rodes, R.M. Kamens, R.W. Wiener. The Significance and Characteristics of the Personal Activity Cloud on Exposure Assessment Measurements for Indoor Contaminants. Indoor Air. 1991;1(2):123-145. doi: 10.1111/j.1600-0668.1991.0312.x

[59] ASHRAE. ANSI/ASHRAE standard 129-1997: Measuring air change effectiveness: American Society of Heating, Refrigerating and Air-Conditioning Engineers, Inc.; 1997.

[60] K. Wladyslaw, B. William, M. Amy. Modeling Immune Building Systems for Bioterrorism Defense. J. Archit. Eng. 2003;9(2):86-96. doi: 10.1061/(ASCE)10760431(2003)9:2(86)

[61] V.A. Bloomfield. Using R for numerical analysis in science and engineering. Boca Raton, FL: Boca Raton, FL : CRC Press; 2014.

[62] K. Soetaert, J. Cash, F. Mazzia. Solving Ordinary Differential Equations in R. 2012 ed. Berlin, Heidelberg: Berlin, Heidelberg: Springer Berlin Heidelberg; 2012.

[63] G.S. Peace. Taguchi methods: a hands-on approach: Addison-Wesley Publishing company; 1993.

[64] W.Y. Fowlkes, C.M. Creveling. Engineering Methods for Robust Product Design: using Taguchi methods in technology and product development. Reading, Massachusetts: Addison-Wesley; 1995.

[65] EFSA Scientific Committee, A. Hardy, D. Benford, T. Halldorsson, M.J. Jeger, K.H. Knutsen, et al. Update: use of the benchmark dose approach in risk assessment. EFSA J. 2017;15(1):e04658-n/a. doi: 10.2903/j.efsa.2017.4658

\section{Appendix A}

Using deSolve solver for sequential box model of airborne contagion dispersal 
The procedures for solving an SBM in deSolve solver involve the following steps:

(a) Download and install the $\mathrm{R}$ statistical environment and R-Studio (integrated development environment for R);

(b) Install and load the ODE solver, i.e., deSolve package;

(c) Formulate the system of ODEs for the SBM of the problem under consideration;

(d) Define the initial conditions (initial values of concentrations at each of the zones), simulation period, and values of other parameters;

(e) Implement the ODEs in the R programming environment;

(f) Solve the systems of ODE, using the 4th order Runge-Kutta method;

(g) Output the results for post-processing.

Step (a) is preliminary as the use of the deSolve package requires the installation of the $\mathrm{R}$ program. For demonstration, the steps above are implemented for the SBM of airborne $M$. bovis decay in a room equipped with upper air ultraviolet germicidal irradiation systems (Nicas and Miller, [21]). For implementation, users can simply copy and paste the syntax into R command window and press CTRL + ENTER key to run.

\section{Install and load the load deSolve package}

The syntax below installs and loads the deSolve package. If the deSolve is already installed, the first command can be omitted.

Install.packages("deSolve") \#\# Install the ODE solver

library(deSolve) \#\# Load the ODE solver package

Formulating the system of ODE for SBM

Consider the sequential box model (SBM) formulation defined by Equation (2) in the main text. Following the steps listed above, an SBM is formulated for the three-zone model (Fig. 2d) of Nicas and Miller [21] study. The SBM consists of three ordinary differential equations that express the dynamics of the spatial distribution of pathogen concentrations in the room. The SBM equations are as follows:

$V_{U} \frac{d C_{U}(t)}{d t}=\beta_{1} C_{L}(t)-\beta_{1} C_{U}(t)-\left(k_{1}+k_{2}\right) V_{U} C_{U}(t)$ 


$$
\begin{aligned}
& V_{L} \frac{d C_{L}(t)}{d t}=\beta_{2} C_{N F}(t)+\beta_{1} C_{U}(t)-\left(\beta_{1}+\beta_{2}+Q+k_{1} V_{L}\right) C_{L}(t) \\
& V_{N F} \frac{d C_{N F}(t)}{d t}=g_{N F}+\beta_{2} C_{L}(t)-\left(\beta_{2}+k_{1} V_{N F}\right) C_{N F}(t)
\end{aligned}
$$

Where, $C_{U}(t), C_{L}(t)$, and $C_{N F}(t)$ refer to the pathogen concentration in the upper, lower, and near-field zones, $V_{U}, V_{L}$, and $V_{N F}$ are the corresponding volumes; and the parameters $\beta_{1}$ : inter-zonal airflow between the upper and lower zones; $\beta_{2}$ : inter-zonal airflow between the near-field and lower zone; $k_{1}, k_{2}$ : the rate constants for biological decay and UV inactivation respectively; $Q$ : airflow rates into the room. Detail values of the initial conditions, simulation periods, and parameters are as shown in Table 3 of the main text. 
Defining the initial condition and model parameters

Solving the SBM in R starts by defining the initial conditions and parameter values. They are created with as vector objects as shown below:

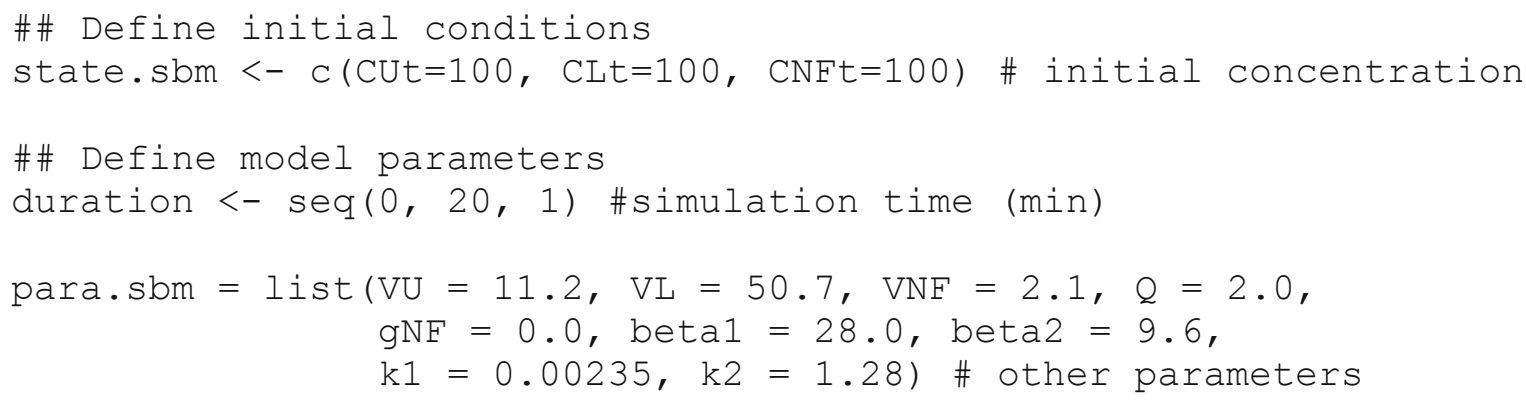

Implementing the ODEs in the $R$ programming environment

To implement SBM requires the definition of a function, which in this case is referred to as sbmfun. The syntax below is used to implement the systems of ODEs for the SBM in R. Users can simply replace the ODEs with the specific problems.

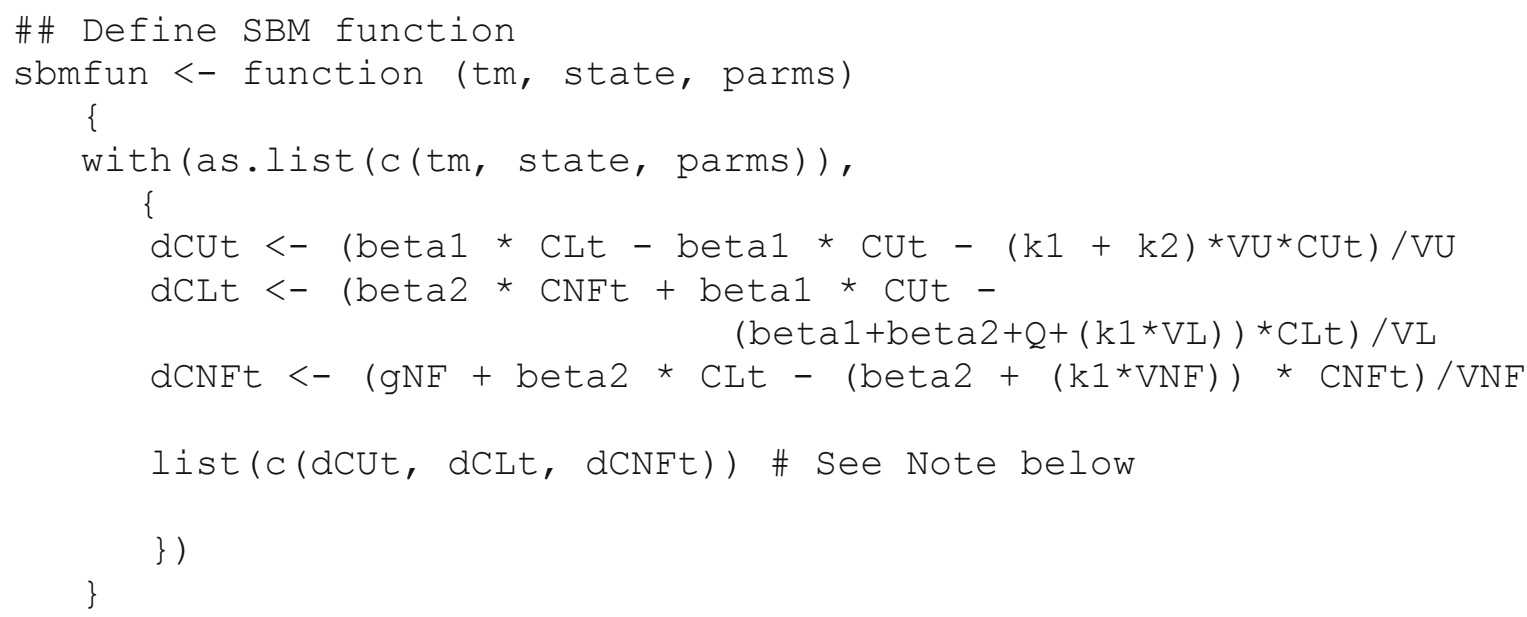

Note: It is essential to return the values of the derivatives, in the same order as the definition of the initial conditions is defined. Doing otherwise may extremely slow down the calculation time.

Solve the systems of ODE, using the 4th order Runge-Kutta method

Subsequent upon the definition of a function, the next step is to solve the system of ODEs, using, for instance, the 4 th order Runge-Kutta method. Other numerical methods can as well be implemented. The ODEs are solved with initial conditions, state.sbm, the parameters, para.sbm, and time, duration; then, the outputs are stored in matrix sol.sbm. The syntax for solving the ODEs is as shown below: 


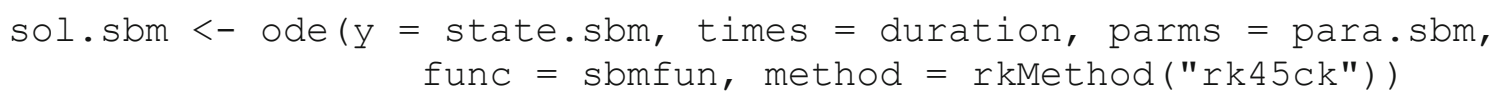

Output the results for post-processing.

The model output in sol.sbm is a matrix consisting of $n+1$ columns, where the first column is time, and $n$ is the number of state variables state. Here, we print the first ten lines of this matrix:

head (sol.sbm, 10)

$\begin{array}{ccccc} & \text { time } & \text { CUt } & \text { CLt } & \text { CNFt } \\ {[1,]} & 0 & 100.00000 & 100.00000 & 100.00000 \\ {[2,]} & 1 & 59.79457 & 84.97821 & 88.57472 \\ {[3,]} & 2 & 48.59021 & 69.61341 & 72.75517 \\ {[4,]} & 3 & 39.77278 & 56.99040 & 59.56686 \\ {[5,]} & 4 & 32.56024 & 46.65576 & 48.76509 \\ {[6,]} & 5 & 26.65573 & 38.19519 & 39.92198 \\ {[7,]} & 6 & 21.82200 & 31.26886 & 32.68253 \\ {[8,]} & 7 & 17.86479 & 25.59855 & 26.75589 \\ {[9,]} & 8 & 14.62518 & 20.95650 & 21.90397 \\ {[10,]} & 9 & 11.97305 & 17.15624 & 17.93189\end{array}$

The output generated (i.e., sol.sbm) by the solver can conveniently be post-processed in $\mathrm{R}$ or exported as comma separated file (or any other formats) for use in external applications. Although the solver can handle dynamic parameters (such as generation rate, inlet concentration, airflow rates, and loss functions), constant values were used in this case study. The consideration of dynamic parameters involves discontinuities in the integration routine, which requires special considerations. Readers may further explore these options for advanced simulations. 